\title{
Do Ruminal Ciliates Select Their Preys and Prokaryotic Symbionts?
}

\author{
Tansol Park and Zhongtang Yu* \\ Department of Animal Sciences, The Ohio State University, Columbus, $\mathrm{OH}$, United States
}

Ruminal ciliates both preys on and form symbiotic relationships with other members of the ruminal microbiota for their survival. However, it remains elusive if they have selectivity over their preys or symbionts. In the present study, we investigated the above selectivity by identifying and comparing the free-living prokaryotes (FLP) and the ciliate-associated prokaryotes (CAP) using Illumina MiSeq sequencing of 16S rRNA gene amplicons. We used single ciliates cells of both monocultures of Entodinium caudatum and Epidinium caudatum and eight different ciliate genera isolated from fresh rumen fluid of dairy cows. Irrespective of the source (laboratory monocultures vs. fresh isolates) of the single ciliate cells, the CAP significantly differed from the FLP in microbiota community profiles. Many bacterial taxa were either enriched or almost exclusively found in the CAP across most of the ciliate genera. A number of bacteria were also found for the first time as ruminal bacteria in the CAP. However, no clear difference was found in methanogens between the CAP and the FLP, which was confirmed using methanogen-specific qPCR. These results suggest that ruminal ciliates probably select their preys and symbionts,

OPEN ACCESS

Edited by:

David William Waite,

University of Auckland, New Zealand

Reviewed by: Jun Gong,

Sun Yat-sen University, China

Pelin Yilmaz,

Max Planck Institute for Marine Microbiology (MPG), Germany

*Correspondence:

Zhongtang Yu yu.226@osu.edu

Specialty section: This article was submitted to

Microbial Symbioses, a section of the journal Frontiers in Microbiology

Received: 19 May 2018 Accepted: 09 July 2018 Published: 31 July 2018

Citation:

Park T and Yu Z (2018) Do Ruminal Ciliates Select Their Preys and

Prokaryotic Symbionts?

Front. Microbiol. 9:1710.

doi: 10.3389/fmich.2018.01710 the latter of which has rarely been found among the free-living ruminal prokaryotes. The bacteria enriched or exclusively found in the CAP can be target bacteria to detect and localize using specific probes designed from their $16 \mathrm{~S}$ rRNA sequences, to characterize using single-cell genomics, or to isolate using new media designed based on genomic information.

Keywords: ruminal ciliates, free-living prokaryotes, ciliate-associated prokaryotes, preys, symbionts

\section{INTRODUCTION}

Rumen protozoa, exclusively ciliates, rank second only to bacteria in cellular biomass of the ruminal microbiota. They are only found in the rumen and similar habitats (Dehority, 1986, 2005) where they play important roles in feed digestion and homeostasis of the rumen ecosystem (Firkins et al., 2007; Newbold et al., 2015). However, they are also blamed for promoting methane $\left(\mathrm{CH}_{4}\right)$ emission due to their mutualistic relationship with methanogens by producing hydrogen (Newbold et al., 1995). Studies using defaunated (free of ruminal ciliates) sheep and cows also provided strong evidence that ruminal ciliates lower nitrogen utilization efficiency in ruminants by decreasing microbial protein supply to the host small intestine due to constant engulfing of bacteria and subsequent bacterial protein degradation inside the rumen (Fondevila and Dehority, 2001). In the early studies (Morgavi et al., 2006; Mosoni et al., 2011), defaunated animals and faunated animals (carrying normal ruminal ciliates) were shown to have different ruminal microbiota, and the difference was postulated as a result of selective predation on and association with ruminal prokaryotes (Dehority, 2003; Belanche et al., 2011). The predator-prey relationship and the symbiotic relationship between ruminal ciliates and prokaryotes have attracted much research interest because both relationships are of biological interest and potential implication in improving ruminant production. 
Studies using fluorescence in situ hybridization (FISH) and electron microscopy revealed the presence of methanogens inside and on the surface of ruminal ciliate cells (Vogels et al., 1980; Finlay et al., 1994; Lloyd et al., 1996; Xia et al., 2014). Several studies (Regensbogenova et al., 2004; Tóthová et al., 2008; Tymensen et al., 2012; Belanche et al., 2014) also revealed differences in the methanogens detected inside and outside of ruminal ciliate cells, but no difference was reported in other studies (Chagan et al., 1999; Tokura et al., 1999; Xia et al., 2014). Using cloning and sequencing of $16 \mathrm{~S}$ rRNA genes, Irbis and Ushida (Irbis and Ushida, 2004) detected Proteobacteria associated with single cells of Polyplastron multivesiculatum, but the P. multivesiculatum cells was pretreated with a mixture of antibiotics, and they did not analyze the free-living bacteria. Studies comparing the bacterial populations between faunated and defaunated sheep revealed differences in bacterial communities, but the difference could not be attributed to selective predation, symbiosis or other microbial interactions, and the bacteria unique to each treatment were not identified (Ozutsumi et al., 2005, 2006; Yánez-Ruiz et al., 2007). Dual symbiosis with both bacteria and methanogens was reported in free-living anaerobic ciliate, Trimyema compressum, which belongs to the same subclass Trichostomatia (Shinzato et al., 2007) as ruminal ciliates. It remains elusive if ruminal ciliates also form specific association with bacteria and methanogens or select their preys. The lack of axenic cultures of ruminal ciliates and inability to develop or maintain such axenic cultures make it difficult to address the above two questions. Our recent study did show that Entodinium caudatum, the most predominant ruminal ciliate species, probably depends on certain prokaryotes for their survival (Park et al., 2017). In the present study, we aimed to identify the prokaryotes that ruminal ciliates select as potential preys or symbionts using monocultures of Ent. caudatum and Epidinium caudatum, and ruminal ciliates of eight genera (Dasytricha, Diplodinium, Diploplastron, Entodinium, Epidinium, Isotricha, Ophryoscolex and Polyplastron) isolated from fresh rumen fluid of dairy cows. Our results provided new insight into the relationship between ruminal ciliates and prokaryotes.

\section{MATERIALS AND METHODS}

\section{Characterization of Ciliate-Associated vs. Free-Living Prokaryotes in Monocultures of Ruminal Ciliates Ent. caudatum and Epi. caudatum}

The monocultures of Ent. caudatum and Epi. caudatum used in the present study were initially established from single cells individually picked from the rumen fluid of a gerenuk and a Jersey dairy cow, respectively (Dehority, 2010). Each monoculture has prokaryotes in addition to the single ciliate

Abbreviations: FLP, free-living prokaryotes; CAP, ciliate-associated prokaryotes; rRNA, ribosomal RNA; FISH, fluorescence in situ hybridization; OTU, operational taxonomic unit; PCoA, principal coordinates analysis; ANOSIM, analysis of similarity; qPCR, quantitative polymerase chain reaction. species. Frozen stock $\left(-80^{\circ} \mathrm{C}\right.$ in SP medium containing $4 \%$ dimethyl sulfoxide) of each monoculture was activated by cultivation in SP medium at $39^{\circ} \mathrm{C}$ and maintained by transfer twice a week under anaerobic conditions with $\mathrm{O}_{2}$-free $\mathrm{CO}_{2}$ gas (Dehority, 1998). The ciliate monocultures were fed daily a ciliate feed as a mixture of ground wheat grain, alfalfa and grass hays (Park et al., 2017). The ciliate cells of each monoculture were counted under a microscope $0,2,4$, and $8 \mathrm{~h}$ after feeding and then fixed with $1 \%$ formalin (Park et al., 2017). Single cells (1-3) of Ent. caudatum and Epi. caudatum were individually picked from the respective fixed monocultures using micropipettes under a microscope connected to a Nikon D50 digital camera (Nikon, Inc., Melville, NY). The single cells were serially transferred at least 5 times in a droplet of sterile phosphate-buffered saline (PBS) followed by 3 additional washes in sterile PBS with low degree centrifugation $(1,000 \times g$ for $3 \mathrm{~min}$ ) to retain the ciliate cells. The supernatant of the finial wash and centrifugation was subjected to PCR amplification using bacteria- and archaea-specific 16S rRNA gene primers (Lane, 1991) to verify if prokaryotes that were loosely-associated with the ciliate cells on their surface had been completely removed (as indicated by negative PCR amplification). Only those washed ciliate cells that had no amplification of bacterial or methanogen $16 \mathrm{~S}$ rRNA genes from their washing supernatant were used in the downstream analysis. Total DNA was extracted from the isolated single ciliate cells using Chelex-100 and Proteinase K as described by Irbis and Ushida (2004). Briefly, after the single ciliate cells were digested using Proteinase $\mathrm{K}$ at $56^{\circ} \mathrm{C}$ for $2 \mathrm{~h}$. Following inactivation of the Proteinase $\mathrm{K}$ by incubation at $95^{\circ} \mathrm{C}$ for $10 \mathrm{~min}$, the lysate was centrifuged $(21,000 \times g$ for $3 \mathrm{~min})$ to separate the supernatant from the cell debris. The supernatant containing the DNA was collected and tested for the presence of ciliate DNA with PCR using ciliate-specific 18S rRNA gene primers (Sylvester et al., 2004) to confirm successful isolation of single ciliate cells. Then, $1 \mathrm{ml}$ of each monoculture was subjected to a series of centrifugation to remove ciliates and prepare FLP. Briefly, $1 \mathrm{ml}$ of each monoculture was centrifuged at $1,000 \times g$ for $3 \mathrm{~min}$ at room temperature to pellet the ciliate cells while leaving the prokaryotes in the supernatant. The supernatant was transferred to a fresh tube and centrifuged again. The supernatant from the second centrifugation was centrifuged at $16,000 \times g$ for $10 \mathrm{~min}$ at $4^{\circ} \mathrm{C}$ to pellet the FLP. Total metagenomic DNA of the FLP was extracted using the repeated bead-beating plus column purification $(\mathrm{RBB}+\mathrm{C})$ method as previously described (Yu and Morrison, 2004). DNA extraction was repeated two more times at different days, and the DNA extracts were combined by ciliate species, prokaryotic fractions, and sampling times.

\section{Identification of Prokaryotes Associated With Single Ciliate Cells Isolated From Fresh Rumen Fluid of Dairy Cows}

Fresh rumen fluid samples were collected $2 \mathrm{~h}$ after morning feeding from 5 rumen-cannulated Jersey dairy cows, which were fed a total mixed ration consisting of corn silage, alfalfa hay, and grounded shelled-corn. Formalin was immediately 
added to the rumen fluid samples to a $1 \%$ final concentration to fix the samples. The generic composition of ruminal ciliates in each rumen fluid sample was determined morphologically as described previously (Baraka, 2012; Martinele et al., 2014). For the ease of isolation of single ciliate cells, the formalinfixed rumen fluid samples were filtered through 50- and $10-\mu \mathrm{m}$ pore-sized nylon filter membrane sequentially (Sefar Filtration Inc., New York, USA) to separate the small-sized dominant Entodinium from other genera. Then, single cells of ciliates were isolated as described above and identified based on their morphologies including cell size, the location of vestibulum and ciliary zone (Baraka, 2012; Martinele et al., 2014). The morphology-based identification was confirmed by sequencing the $18 \mathrm{~S}$ rRNA gene amplified using ciliate-specific primers (Sylvester et al., 2004) and sequence comparison using BLAST against GenBank. Eight different genera of ruminal ciliates were successfully isolated as single cells and identified to known ruminal ciliate genera. The GenBank accession numbers and sequence identity of the isolated single ruminal ciliate cells, including those of the monocultures of Ent. caudatum and Epi. caudatum, were shown in Table S1. From the isolated single cells of ciliates and the FLP, metagenomic DNA was extracted as described above.

\section{Microbiota Analysis Using Amplicon Sequencing}

The CAP and the FLP were identified using Illumina MiSeq sequencing and analysis of $16 \mathrm{~S}$ rRNA gene amplicons of the V4-V5 hypervariable regions essentially as described previously (Kigerl et al., 2016). Briefly, primers 515F (5'-GTGCCAGCM GCCGCGGTAA- $\left.3^{\prime}\right)$ and 806R (5'-GGACTACHVGGGTWT CTAAT-3') were used to amplify the V4-V5 region of both bacteria and methanogens (Caporaso et al., 2011). The purified amplicon libraries (each having a unique barcode sequence) of all the DNA extracts were pooled and sequenced using the $2 \times 300$ paired-end chemistry. The sequence data were processed using QIIME with the default options applied (ver.1.9.1) (Caporaso et al., 2010). The two paired-end reads were joined, and lowquality reads $(\mathrm{Q}<25)$ were filtered out followed by trimming of barcode and primer sequences. Then, the joined sequences shorter than $200 \mathrm{bp}$ or longer than $600 \mathrm{bp}$ were discarded. Sequences with any homopolymers longer than $6 \mathrm{nt}$ were removed, and the quality-checked sequences $(\mathrm{Q}>25)$ were merged into a single Fasta file. Operational taxonomic units were picked using the open-reference OTU picking method against the Greengenes reference set (ver. 13_8) (DeSantis et al., 2006) at 97\% similarity using PyNAST (Caporaso et al., 2010). Those sequences that failed to cluster with the Greengenes reference OTUs were clustered into OTUs de novo at $97 \%$ sequence similarity. Probable chimeric sequences were predicted using ChimeraSlayer with the default options applied against the Greengenes aligned reference sequences (DeSantis et al., 2006) and removed. The OTUs of methanogens were separated from the bacterial OTUs in the Biom OTU tables so that methanogens and bacteria could be analyzed separately. Taxonomic classification was determined using the RDP Classifier with $80 \%$ confidence (Wang et al., 2007). Relative abundance of a taxon was expressed as its \% of sequences relative to total sequences in respective samples.

$\alpha$-diversity measurements, including observed number of OTUs, Shannon diversity index $\left(H^{\prime}\right)$, Simpson's index of diversity (1-D), Chao 1 species richness estimate, and phylogenetic diversity ( $\mathrm{PD}$ _whole_tree), were calculated from rarefied Biom OTU tables. Principal coordinates analysis (PCoA) based on unweighted UniFrac distances (Lozupone and Knight, 2005) was used to compare the overall microbiota between the CAP and the FLP of all ciliate species. The CAP-specific bacterial 16S rRNA amplicon sequences shared by ciliate single cells were used to generate a maximum likelihood tree using MEGA6 with 1,000 bootstraps (Tamura et al., 2013). The raw sequence reads were deposited into the Sequence Read Archive (SRA) of NCBI under the accession number PRJNA476351.

\section{Quantification of Methanogen Abundance Using Quantitative PCR}

The abundance of total methanogens, genus Methanobrevibacter, class Thermoplasmata, family Methanosarcinaceae, and species Methanosphaera stadtmanae, all of which were detected in the CAP and the FLP of the isolated ciliate single cells, was quantified as copies of $16 \mathrm{~S}$ rRNA genes using respective group-specific primer sets and a nested PCR approach as described by Tymensen et al. (2012). A nested PCR was used because of the low abundance of methanogens in the CAP extracts. Briefly, amplicons representing total methanogens were generated from each of the DNA extracts using PCR and primers Met86f/Met915r (Wright and Pimm, 2003; Watanabe et al., 2004) and then purified using a QIAquick PCR purification kit (Qiagen, Inc., Valencia, CA). The purified PCR product (diluted 1:100) was used as the enriched methanogens 16S rRNA gene templates for qPCR quantification. One sample-derived qPCR standard (Yu et al., 2005) was prepared for each methanogen group using PCR with respective group-specific primers (Table S2) using a DNA extract from one FLP sample that had all the methanogen targets detected in the sequencing analysis. Ten-fold serial dilutions $\left(10^{1}-10^{9} 16 \mathrm{~S}\right.$ rRNA gene amplicons per $\left.\mu \mathrm{l}\right)$ were prepared for each qPCR standard and used in qPCR analysis as described previously (Wang et al., 2012). The qPCR cycles included initial denaturation at $95^{\circ} \mathrm{C}$ for $10 \mathrm{~min}$, followed by 40 cycles $\left(95^{\circ} \mathrm{C}\right.$ for $30 \mathrm{~s}, 60^{\circ} \mathrm{C}$ for $30 \mathrm{~s}, 72^{\circ} \mathrm{C}$ for $30 \mathrm{~s}$ ) and a final extension for $5 \mathrm{~min}$ at $72^{\circ} \mathrm{C}$. For enumeration of Methanobrevibacter spp., the annealing temperature was $63^{\circ} \mathrm{C}$. Melting curves generated between 52 and $95^{\circ} \mathrm{C}$ in each run were checked to verify the specificity of qPCR amplification.

\section{Statistical Analysis}

For the monocultures of Ent. caudatum and Epi. caudatum, the relative abundance of each taxon and the abundance of the quantified methanogen groups in the two prokaryotic fractions (FLP vs. CAP) at different time after feeding $(0,2,4$, and $8 \mathrm{~h}$ ) were statistically analyzed using the GLIMMIX procedure of SAS 9.4 (SAS Institute Inc., Cary, NC). Prokaryotic fraction $\mathrm{x}$ time post feeding (fraction $\times$ time) interaction was also examined. For the single ciliate cells from the two ciliate monocultures, a 
polynomial contrast was used to analyze the population shift of the CAP and the FLP over time of incubation. Relative abundance of taxa among ciliate genera was compared using the GLIMMIX procedure of SAS with animal as a random effect. The Scheffe post-hoc test was used to examine significant differences between the FLP and CAP from the rumen fluid. For the monocultures of Ent. caudatum and Epi. caudatum and the fresh rumen fluid, significant differences in the overall microbiota between the CAP and the FLP were estimated using ANOSIM (Clarke and Gorley, 2006) implemented in QIIME based on the unweighted UniFrac distances. The significance was declared at $P \leq 0.05$.

\section{RESULTS}

\section{Free-Living and Ciliate-Associated Prokaryotes in the Monocultures of Ent. caudatum and Epi. caudatum Bacteria}

Except for the Shannon-Wiener diversity index of both ciliate monocultures and the Simpson diversity index of the Epi. caudatum monoculture, all the $\alpha$-diversity measurements differed between the CAP and the FLP (Table 1). More operational taxonomic units (OTUs) were found and predicted (Chaol richness) in the FLP than in the CAP even though the FLP had a lower depth coverage than the CAP. On the PCoA plot, the CAP and the FLP of each ciliate monoculture were separated along PC1, while the CAP and the FLP of both ciliate monocultures were separated along PC2 (Figure 1A). Based on the analysis of similarity (ANOSIM) method, the CAP differed $(P<0.001)$ from the FLP for both ciliate monocultures, and the two ciliate monocultures had different $(P<0.001)$ prokaryotic populations for both the CAP and the FLP. No significant change was found in all the $\alpha$-diversity measurements of the CAP for both ciliate monocultures over the $8 \mathrm{~h}$ after feeding, except a linear decrease in the number of observed OTUs $(P=0.033)$, a tendency of linear decrease in Chaol species richness estimate $(P=0.090)$, and phylogenetic diversity $(P=0.024)$ of the Ent. caudatum monoculture (Figure 2A). In the FLP of both monocultures, no significant postprandial change in both relative abundance of major taxa ( $>0.5 \%$ of total sequences) and all the $\alpha$-diversity measurements (data not shown).

In both the CAP and the FLP of the two ciliate monocultures, the relative abundance of all the identified taxa at all the taxonomic ranks did not change over the $8 \mathrm{~h}$ after feeding, except that the relative abundance of Sediminibacterium, a genus of Bacteroidetes, in the CAP of Ent. caudatum monoculture quadratically decreased $(P=0.059)$ (Figure $2 B$ ), and that of Succinivibrio tended $(P=0.067)$ to linearly increase in the CAP of the Epi. caudatum monoculture (Figure 2C).

The bacterial profiles differed to a greater extent at low (e.g., genus) than at high taxonomic ranks (e.g., phylum) between the two fractions and between the two ciliate monocultures (Figure 3 and Table 2). Among the detected bacterial phyla, Acidobacteria, Actinobacteria, Cyanobacteria, Planctomycetes, and Proteobacteria were significantly more predominant $(P<0.05)$ in the CAP than in the FLP of both ciliate monocultures, whereas Bacteroidetes and Spirochaetes showed the opposite distributions. Bacteroidetes and Proteobacteria were the two largest phyla in both the CAP and the FLP, and they exhibited opposite distributions between the two prokaryotic fractions. Fibrobacteres had a greater relative abundance in the FLP than in the CAP of the Ent. caudatum monoculture but similar predominance between the two prokaryotic fractions of the Epi. caudatum monoculture. Bacteroidia was about three times more predominant in the FLP than in the CAP (Figure 3). Among Proteobacteria, the classes $\alpha-, \beta$-, and $\delta$ Proteobacteria were nearly exclusively found in the CAP, whereas $\gamma$-Proteobacteria was found in both the CAP and the FLP of both ciliate monocultures, but it was much more predominant in the FLP. Among the known genera detected, Prevotella and Ruminobacter were the first and the second largest genera in the Ent. caudatum monoculture, while Succinivibrio and Prevotella were the first and the second largest genera in the Epi. caudatum monoculture. For both ciliate monocultures, Prevotella was more predominant in the FLP than in the CAP, whereas the opposite was true for Sediminibacterium, Butyrivibrio, Limnobacter, Perlucidibaca, and Nevskia. Coprococcus displayed opposite distribution in the CAP and the FLP between the two ciliate monocultures, being more predominant in the CAP of Ent. caudatum monoculture but more predominant in the FLP of Epi. caudatum monoculture. Fibrobacter was the sole known genus in Fibrobacteres detected, and it was significantly more predominant in the FLP than in the CAP of the Ent. caudatum monoculture. No significant temporal differences in relative abundance of the major bacterial taxa ( $>1 \%$ of total sequences) were found for both fractions and both ciliate monocultures (data not shown).

The Ent. caudatum and Epi. caudatum single cells shared nine taxa that were detected only in the CAP (Figure 4). Two phyla, Acidobacteria and Actinobacteria, were almost exclusively found in the CAP of both ciliate species. Among the Bacteroidetes, the genus Sediminibacterium was only found in the CAP. One candidate order (Ellin329), 2 families (Bradyrhizobiaceae and Rhodospirillaceae) of $\alpha$-Proteobacteria, and one candidate family of $\gamma$-Proteobacteria (Sinobacteraceae UN1) were CAP-specific taxa. Of all the CAP, 60.7 and 39.9\% were exclusively found within the CAP of Ent. caudatum and Epi. caudatum cells, respectively. The two ciliate monocultures also had a different relative abundance of several genera, including Prevotella, Sediminibacterium, Butyrivibrio, Coprococcus, Ruminococcus, Ruminobacter, and Succinivibrio (Table 2).

\section{Methanogens}

Methanogens were represented by $<1 \%$ of the total sequences for both ciliate monocultures (Ent. caudatum $=0.54 \%$, Epi. caudatum $=0.73 \%$ ), all of which were assigned to the phylum Euryarchaeota (Table 3A). Methanobrevibacter and class Thermoplasmata were the largest taxa found in both ciliate monocultures without significant temporal variation in abundances after feeding, and these two taxa had $>3$-fold greater predominance in the FLP than in the CAP of the Ent. caudatum monoculture but similar relative abundance in the two prokaryotic fractions of Epi. caudatum monoculture. 
TABLE 1 | Summary of $\alpha$-diversity measurements.

\begin{tabular}{|c|c|c|c|c|c|c|c|c|c|}
\hline Ciliate genera & $\begin{array}{c}\text { Prokaryotic } \\
\text { fraction* }\end{array}$ & $\begin{array}{c}\text { Raw } \\
\text { sequences }\end{array}$ & $\begin{array}{c}\text { Quality } \\
\text { sequences }\end{array}$ & $\begin{array}{l}\text { No. of } \\
\text { OTUs }\end{array}$ & Chao1 & Simpson & Shannon & $\begin{array}{c}\text { Phylogenetic } \\
\text { diversity }\end{array}$ & $\begin{array}{c}\text { Goods } \\
\text { Coverage (\%) }\end{array}$ \\
\hline \multicolumn{10}{|l|}{ MONOCULTURES } \\
\hline \multirow[t]{2}{*}{ Entodinium caudatum } & FLP & $80,257^{a}$ & $5,616^{a}$ & $125^{a}$ & $248^{a}$ & $0.91^{b}$ & 5.09 & $16.6^{a}$ & $86.1^{\mathrm{b}}$ \\
\hline & CAP & $14,882^{b}$ & $1,182^{b}$ & $78^{b}$ & $96^{b}$ & $0.95^{\mathrm{a}}$ & 5.24 & $12.3^{b}$ & $95.9^{\mathrm{a}}$ \\
\hline \multirow[t]{2}{*}{ Epidinium caudatum } & FLP & $66,454^{a}$ & $6,505^{a}$ & $102^{a}$ & $230^{a}$ & 0.85 & 4.35 & $15.4^{\mathrm{a}}$ & $88.1^{\mathrm{b}}$ \\
\hline & CAP & $15,241^{b}$ & $1,906^{b}$ & $75^{b}$ & $92^{b}$ & 0.89 & 4.71 & $12.8^{b}$ & $95.7^{a}$ \\
\hline \multicolumn{10}{|c|}{ FRESHLY ISOLATED CILIATES } \\
\hline Rumen fluid & FLP & 43,316 & 33,630 & $269^{a}$ & $443^{a}$ & 0.95 & $6.46^{a}$ & 26.3 & $90.1^{\mathrm{b}}$ \\
\hline Dasytricha & CAP & 47,162 & 15,239 & $80^{b}$ & $96^{b}$ & 0.96 & $5.33^{b}$ & $13.5^{C}$ & $98.9^{a}$ \\
\hline Diplodinium & CAP & 28,224 & 10,505 & $87^{b}$ & $100^{b}$ & 0.97 & $5.45^{b}$ & $14.3^{\mathrm{bc}}$ & $98.8^{a}$ \\
\hline Diploplastron & CAP & 46,066 & 24,845 & $130^{b}$ & $144^{b}$ & 0.97 & $6.02^{a b}$ & $19.6^{b}$ & $98.3^{a}$ \\
\hline Entodinium & CAP & 39,364 & 20,029 & $111^{b}$ & $128^{b}$ & 0.96 & $5.56^{b}$ & $16.2^{\mathrm{bc}}$ & $98.2^{\mathrm{a}}$ \\
\hline Epidinium & CAP & 32,375 & 16,601 & $95^{b}$ & $110^{\mathrm{b}}$ & 0.97 & $5.66^{b}$ & $15.4^{\mathrm{bc}}$ & $98.8^{a}$ \\
\hline Isotricha & CAP & 34,608 & 12,699 & $97^{\mathrm{b}}$ & $111^{b}$ & 0.96 & $5.56^{b}$ & $15.5^{\mathrm{bc}}$ & $98.7^{\mathrm{a}}$ \\
\hline Ophryoscolex & CAP & 35,344 & 16,677 & $109^{b}$ & $127^{b}$ & 0.97 & $5.68^{b}$ & $17.4^{\mathrm{bc}}$ & $98.3^{a}$ \\
\hline Polyplastron & CAP & 44,884 & 21,163 & $99^{b}$ & $116^{b}$ & 0.94 & $5.39^{b}$ & $15.7^{\mathrm{bc}}$ & $98.5^{a}$ \\
\hline
\end{tabular}

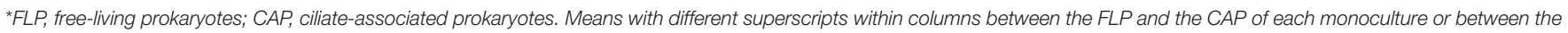
FLP and the CAP of the fresh ciliate isolates differ $(P<0.05)$.

\# Singleton was removed.

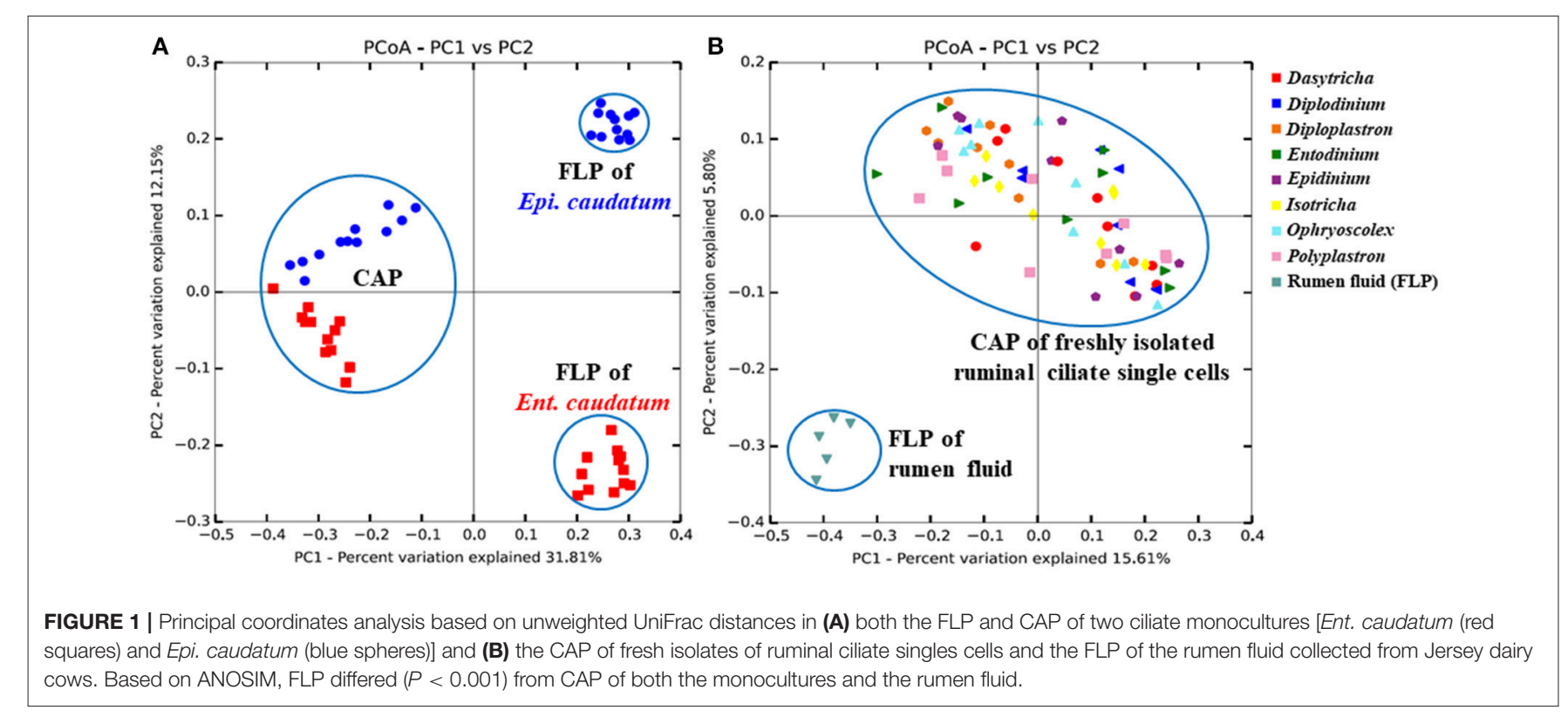

Among the 12 isolated single cells of each ciliate species, seven of the Ent. caudatum cells and 4 of the Epi. caudatum cells yielded no methanogen sequences. In both ciliate monocultures, Methanosphaera was only found in the FLP at low frequency.

The abundance of total methanogens and four methanogenic archaeal taxa (Methanobrevibacter, Thermoplasmata, Methanosarcinaceae, and Methanosphaera stadtmanae) were quantified using specific qPCR. The relative abundance of Methanosarcinaceae was less than $0.001 \%$ of total methanogens, and it was not further discussed. The relative (relative to total prokaryotes) abundance of total methanogens determined by
qPCR was in line with that determined from the sequencing data (Table 4). Compared with the CAP, the FLP of the Epi. caudatum monoculture had a greater relative abundance of total methanogens, Thermoplasmata, and M. stadtmanae (Table 4). The two prokaryotic fractions of Ent. caudatum monoculture had a similar relative abundance of all the groups of methanogens quantified. The relative abundance of Thermoplasmata in the CAP of the Ent. caudatum monoculture cubically fluctuated temporally after feeding, while that of Methanobrevibacter of the Epi. caudatum monoculture decreased overtime linearly after feeding (Figure S1). 

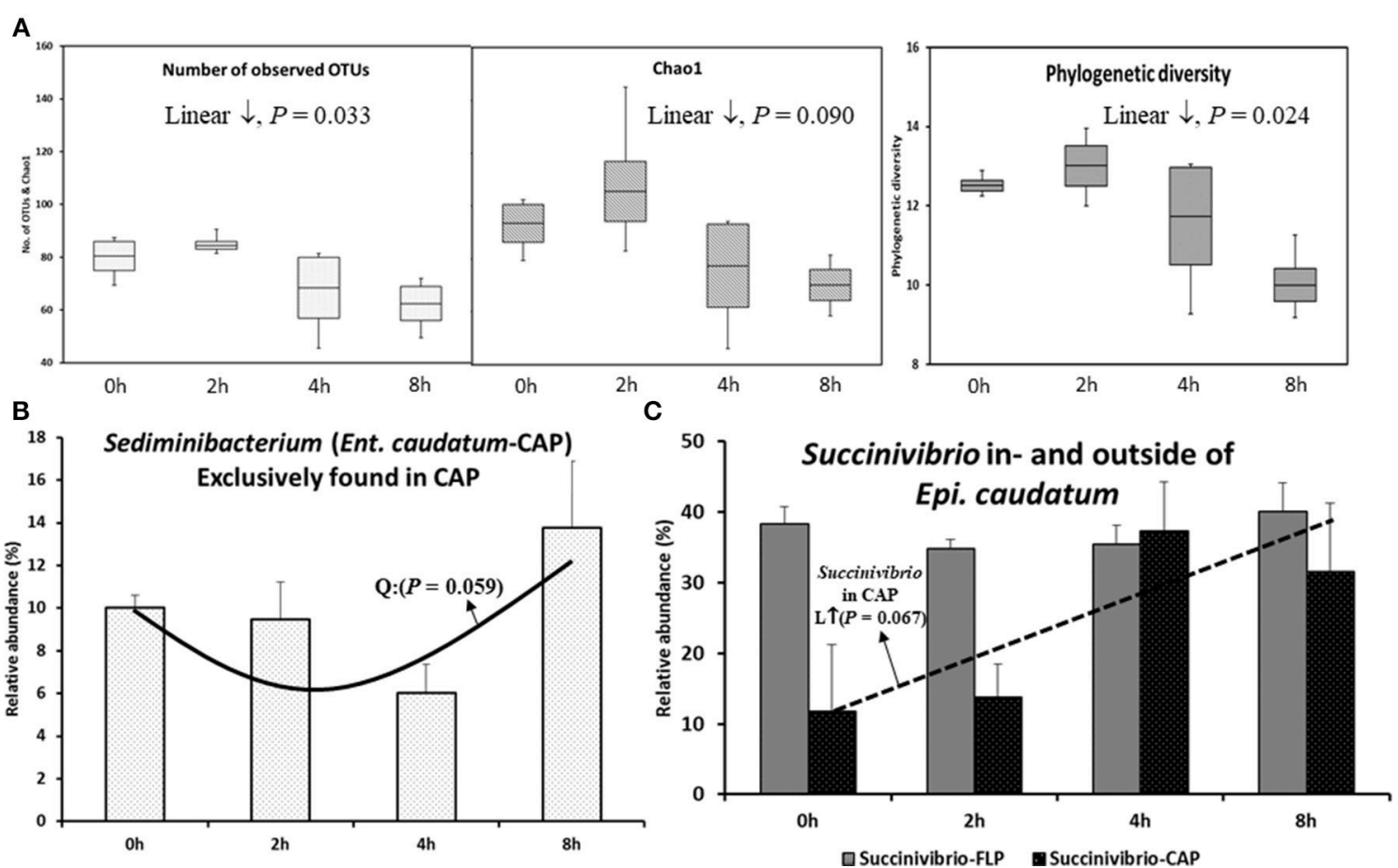

FIGURE 2 | Temporal changes in species richness, phylogenetic diversity, and relative abundance of select taxa after feeding. (A) $\alpha$-diversity measurements in the CAP of Ent. caudatum. (B) Sediminibacterium in the CAP of Ent. caudatum, and (C) Succinivibrio found in- and outside of Epi. caudatum cells. No significant temporal changes of $\alpha$-diversity measurements were found in Epi. caudatum.
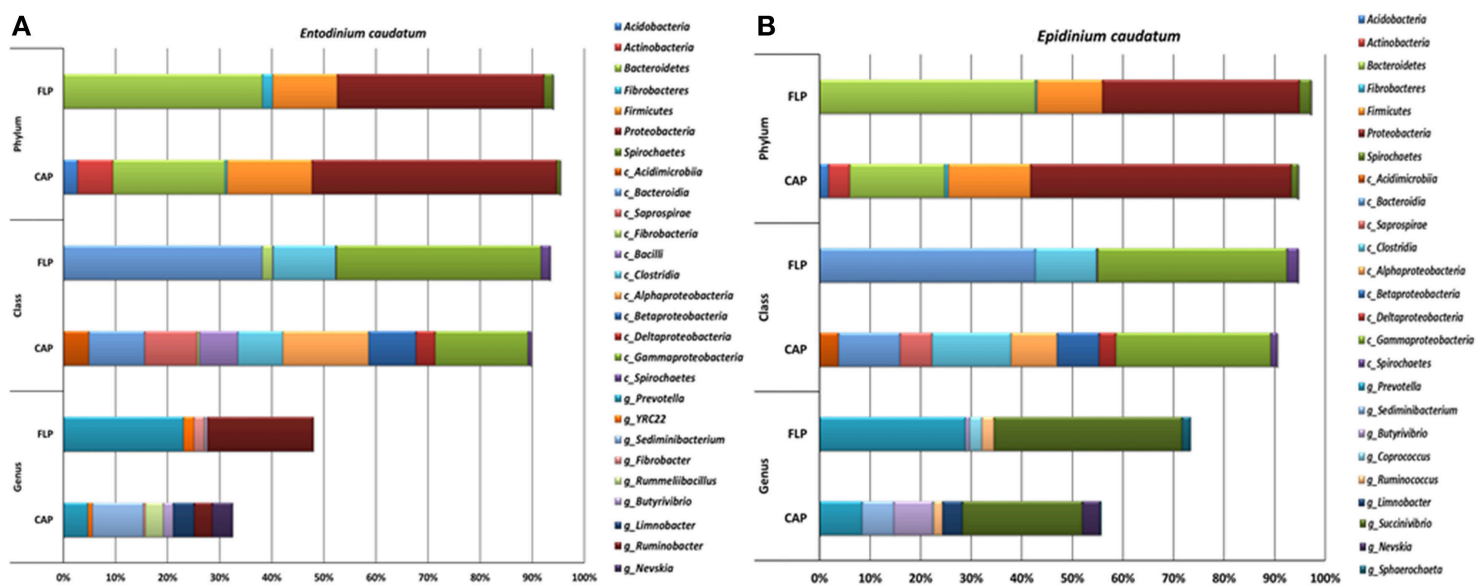

FIGURE 3 | Relative abundance of bacterial phyla, classes and known genera in the CAP and the FLP of the monocultures of Ent. caudatum (A) and Epi. caudatum (B) Relative abundance did not add up to $100 \%$ because unclassified bacterial taxa were not included.

\section{Free-Living and Ciliate-Associated Prokaryotes in the Fresh Rumen Fluid} Ciliate Populations

We found and identified eight genera of ruminal ciliates from the rumen fluid collected from dairy cows fed a typical lactating diet (Figure S2). Morphological identification of these genera was confirmed by sequencing their $18 \mathrm{~S}$ rRNA genes. Entodinium dominated the total ciliates in all the five cows sampled, accounting for greater than $94 \%$ of the total ciliates (Table S3).

\section{Bacteria}

More than 1.2 million quality-checked sequences afforded a depth coverage $>98 \%$ of the CAP of the single ciliate cells isolated from fresh rumen fluid (referred to as single ciliate cells of fresh rumen fluid henceforth) (Table 1). Overall, these 
TABLE 2 | Relative abundances (\%) of major known bacterial taxa* in the FLP and the CAP of the monocultures of Ent. caudatum and Epi. caudatum.

\begin{tabular}{|c|c|c|c|c|c|c|c|c|}
\hline \multirow{3}{*}{$\begin{array}{l}\text { Phylum } \\
\text { Lowest taxa assigned }^{\star *}\end{array}$} & \multicolumn{4}{|c|}{ Relative abundance $(\%)^{\star}$} & \multicolumn{3}{|c|}{$P$-value } & \multirow{3}{*}{ Detection in CAP } \\
\hline & \multicolumn{2}{|c|}{ Ent. caudatum } & \multicolumn{2}{|c|}{ Epi. caudatum } & \multirow{2}{*}{$\begin{array}{l}\text { Ent. } \\
\text { vs. Epi. }\end{array}$} & \multirow{2}{*}{$\begin{array}{l}\text { CAP } \\
\text { vs. FLP }\end{array}$} & \multirow{2}{*}{$\begin{array}{l}\text { Species } x \\
\text { fraction }\end{array}$} & \\
\hline & FLP & CAP & FLP & CAP & & & & \\
\hline Acidobacteria & 0 & 2.43 & 0 & 1.79 & 0.251 & $<0.001$ & 0.251 & Only \\
\hline o_Ellin6513 & 0 & 1.40 & 0 & 0.71 & 0.058 & $<0.001$ & 0.058 & Only \\
\hline Actinobacteria & 0.02 & 6.89 & 0 & 4.38 & 0.051 & $<0.001$ & 0.054 & Enriched \\
\hline c_Actinobacteria & 0 & 1.75 & 0 & 0.42 & 0.101 & 0.009 & 0.101 & Only \\
\hline o_Acidimicrobiales & 0 & 5.10 & 0 & 3.96 & 0.260 & $<0.001$ & 0.260 & Only \\
\hline Bacteroidetes & 38.6 & 21.0 & 44.0 & 18.8 & 0.312 & $<0.001$ & 0.020 & \\
\hline o_Bacteroidales & 38.6 & 10.2 & 44.0 & 12.1 & 0.021 & $<0.001$ & 0.241 & \\
\hline $\mathrm{f} \_B S 11$ & 5.71 & 0.42 & 2.35 & 0.03 & $<0.001$ & $<0.001$ & $<0.001$ & \\
\hline f_Paraprevotellaceae & 2.01 & 1.03 & 0.31 & 0.34 & $<0.001$ & 0.057 & 0.042 & \\
\hline g_Prevotella & 23.5 & 4.78 & 29.8 & 8.54 & 0.015 & $<0.001$ & 0.529 & \\
\hline g_Sediminibacterium & 0 & 9.99 & 0 & 6.47 & 0.028 & $<0.001$ & 0.028 & Only \\
\hline Cyanobacteria & 0 & 0.80 & 0.02 & 1.82 & 0.118 & $<0.001$ & 0.130 & Enriched \\
\hline Fibrobacteres & 1.64 & 0.43 & 0.31 & 0.37 & 0.003 & 0.014 & 0.007 & \\
\hline Firmicutes & 12.1 & 15.5 & 12.7 & 15.4 & 0.901 & 0.130 & 0.876 & \\
\hline c_Bacilli & 0.15 & 6.93 & 0.13 & 0.31 & 0.020 & 0.015 & 0.020 & Enriched \\
\hline o_Bacillales & 0.15 & 5.49 & 0 & 0.21 & 0.045 & 0.041 & 0.058 & Enriched \\
\hline o_Clostridiales & 11.7 & 8.38 & 11.7 & 14.8 & 0.024 & 0.930 & 0.024 & \\
\hline f_Planococcaceae & 0.15 & 3.68 & 0 & 0.03 & 0.143 & 0.168 & 0.175 & \\
\hline f_Lachnospiraceae & 6.18 & 4.05 & 3.54 & 8.61 & 0.366 & 0.167 & 0.001 & \\
\hline g_Butyrivibrio & 0.48 & 1.91 & 0.82 & 7.24 & 0.004 & $<0.001$ & 0.009 & Enriched \\
\hline g_Coprococcus & 0 & 0.52 & 2.16 & 0.35 & $<0.001$ & 0.021 & $<0.001$ & \\
\hline f_Ruminococcaceae & 1.88 & 1.61 & 3.62 & 2.59 & 0.005 & 0.168 & 0.420 & \\
\hline g_Ruminococcus & 0.29 & 0.93 & 2.46 & 1.79 & $<0.001$ & 0.964 & 0.070 & \\
\hline Planctomycetes $^{\dagger}$ & 0.06 & 1.77 & 0.10 & 1.54 & 0.622 & $<0.001$ & 0.511 & Enriched \\
\hline c_Planctomycetia & 0.06 & 1.08 & 0.10 & 1.16 & 0.799 & $<0.001$ & 0.913 & Enriched \\
\hline f_Isosphaeraceae & 0 & 1.03 & 0 & 1.08 & 0.911 & $<0.001$ & 0.911 & Only \\
\hline Proteobacteria & 40.1 & 48.7 & 38.4 & 53.0 & 0.561 & $<0.001$ & 0.193 & Enriched \\
\hline c_ $\alpha$-Proteobacteria & 0 & 16.3 & 0 & 9.23 & 0.020 & $<0.001$ & 0.020 & Only \\
\hline o_Ellin329 & 0 & 5.66 & 0 & 3.51 & 0.124 & $<0.001$ & 0.124 & Only \\
\hline o_Rhizobiales & 0 & 6.03 & 0 & 3.36 & 0.058 & $<0.001$ & 0.058 & Only \\
\hline f_Bradyrhizobiaceae & 0 & 4.60 & 0 & 2.37 & 0.026 & $<0.001$ & 0.026 & Only \\
\hline f_Rhodospirillaceae & 0 & 3.17 & 0 & 1.66 & 0.012 & $<0.001$ & 0.012 & Only \\
\hline c_ $\beta$-Proteobacteria & 0.15 & 9.57 & 0.06 & 7.90 & 0.372 & $<0.001$ & 0.417 & Enriched \\
\hline o_Burkholderiales & 0.15 & 6.15 & 0.06 & 5.34 & 0.507 & $<0.001$ & 0.587 & Enriched \\
\hline f_Comamonadaceae & 0.05 & 5.94 & 0 & 5.04 & 0.479 & $<0.001$ & 0.525 & Enriched \\
\hline g_Limnobacter & 0 & 3.94 & 0 & 3.68 & 0.857 & $<0.001$ & 0.857 & Only \\
\hline c_ $\delta$-Proteobacteria & 0.06 & 4.20 & 0.24 & 3.60 & 0.659 & $<0.001$ & 0.417 & Enriched \\
\hline o_Myxococcales & 0 & 4.07 & 0 & 3.04 & 0.234 & $<0.001$ & 0.234 & Only \\
\hline f_0319-6G20 & 0 & 2.57 & 0 & 1.63 & 0.112 & $<0.001$ & 0.112 & Only \\
\hline$c_{-} \gamma$-Proteobacteria & 39.7 & 18.6 & 36.6 & 32.0 & 0.035 & $<0.001$ & 0.001 & \\
\hline f_Succinivibrionaceae ${ }^{\dagger}$ & 39.6 & 7.35 & 36.4 & 24.6 & 0.013 & $<0.001$ & $<0.001$ & \\
\hline g_Ruminobacter & 20.7 & 3.96 & 0 & 0.10 & $<0.001$ & $<0.001$ & $<0.001$ & \\
\hline g_Succinivibrio & 0.27 & 0.35 & 36.3 & 24.4 & $<0.001$ & 0.020 & 0.019 & \\
\hline f_Moraxellaceae ${ }^{\dagger}$ & 0.02 & 1.71 & 0 & 1.08 & 0.129 & $<0.001$ & 0.148 & Enriched \\
\hline g_Perlucidibaca & 0 & 1.30 & 0 & 0.74 & 0.191 & $<0.001$ & 0.191 & Only \\
\hline o_Xanthomonadales & 0 & 9.22 & 0 & 6.08 & 0.072 & $<0.001$ & 0.072 & Only \\
\hline f_Sinobacteraceae & 0 & 7.88 & 0 & 5.66 & 0.101 & $<0.001$ & 0.101 & Only \\
\hline g_Nevskia & 0 & 4.04 & 0 & 3.76 & 0.789 & $<0.001$ & 0.789 & Only \\
\hline Spirochaetes & 1.69 & 0.66 & 2.04 & 1.14 & 0.316 & 0.024 & 0.877 & \\
\hline g_Sphaerochaeta & 1.29 & 0.08 & 1.51 & 0.21 & 0.595 & $<0.001$ & 0.885 & \\
\hline
\end{tabular}

*Only the taxa with a relative abundance greater than $1 \%$ at the lowest taxonomic rank were shown.

${ }^{* \star}$ C, Class; o, Order; f, Family; g, Genus.

\#Found only or significantly enriched in the CAP in both monocultures.

${ }^{\dagger}$ For those taxa, only the lowest classifiable taxa were shown because their higher taxa had similar relative abundance as the taxa shown. 

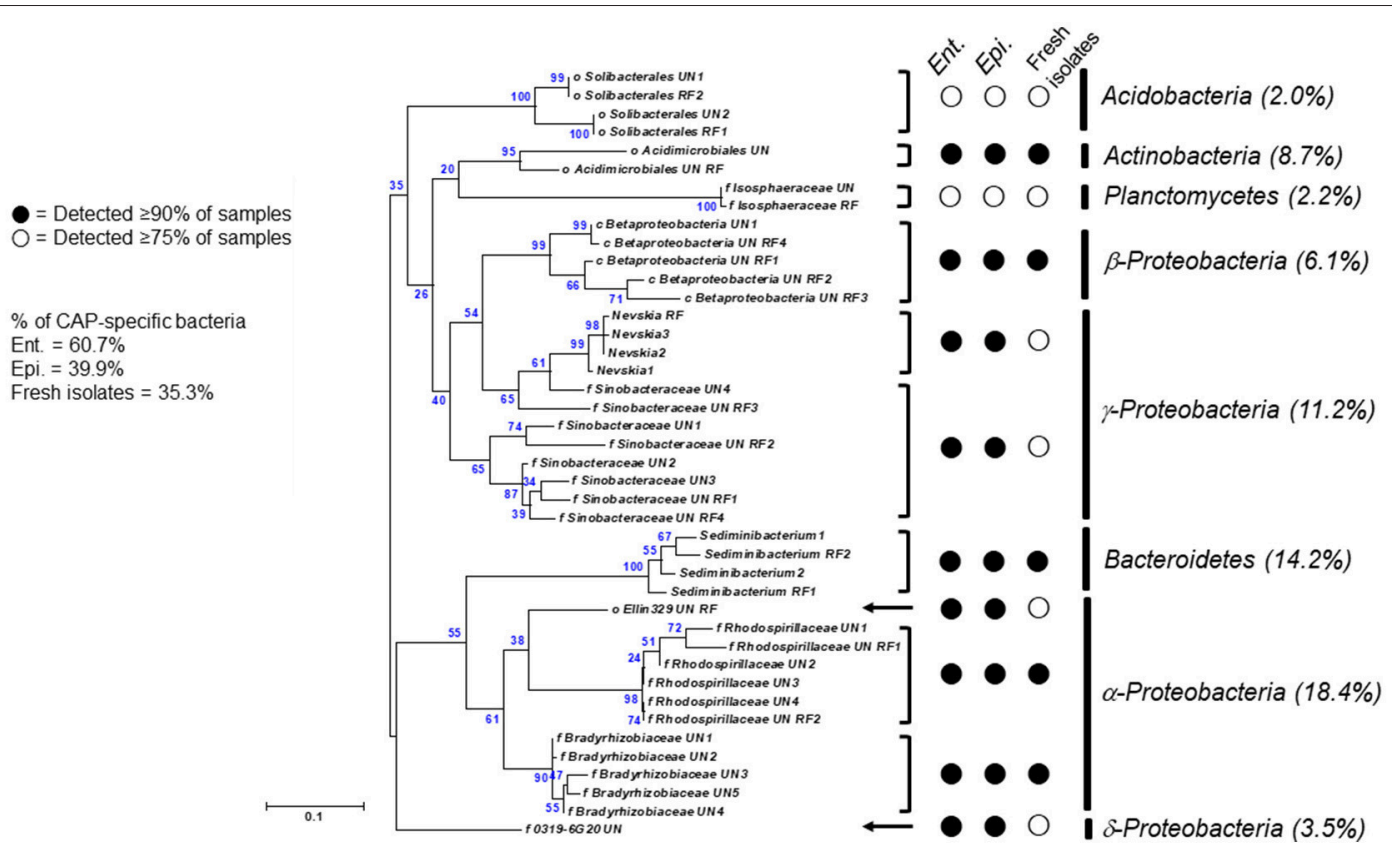

FIGURE 4 | A maximum-likelihood tree showing CAP-specific bacterial 16S rRNA gene sequences shared by ciliate single cells [18 sequences from the freshly isolated ciliate single cells and 24 sequences from Ent. caudatum (Ent.) and Epi. caudatum (Epi.) in their monocultures]. Relative abundance of each taxon among CAP-specific bacteria was shown in parentheses. Minor taxa ( $<0.5 \%$ of total sequences) were excluded.

single cells had smaller $\alpha$-diversity measurements of prokaryotes than the rumen fluid except for Simpson's diversity index. On the PCoA plot (Figure 1B), the FLP of rumen fluid formed a cluster that is separate from that of the CAP of the fresh rumen fluid along both PC1 and PC2. Based on ANOSIM, the overall FLP and the CAP of rumen fluid were distinct $(P<0.001)$.

Overall, the CAP had a greater predominance of Proteobacteria than the FLP, whereas the latter had a greater predominance of Bacteroidetes, Firmicutes, and Fibrobacteres than the former (Figure 5A). Compared to the FLP, the CAP also had a greater relative abundance of Acidobacteria (1.38 vs. $0 \%, P=0.048$ ), Actinobacteria ( 3.74 vs. $0.08 \%, P=0.021$ ) and Proteobacteria (32.8 vs. $12.2 \%, P<0.001$ ), but lower relative abundance of Bacteroidetes ( 30.5 vs. $42.4 \%, P=0.003$ ), Firmicutes (16.6 vs. 32.4\%, $P<0.001$ ) and Spirochaetes (2.69 vs. $6.45 \%, P=0.005)$. Among the known genera detected, Prevotella (28.4 vs. $17.1 \%, P<0.001)$ and Coprococcus $(4.26$ vs. $0.97 \%, P=0.054$ ) were more predominant in the FLP than in the CAP, whereas Sediminibacterium, Limnobacter, and Nevskia were only detected in the CAP (Figure 5B and Table 5). However, despite the overall difference between the FLP and the CAP, the distribution of each assigned taxon varied depending on the genera of the host ciliates (Table 5). Thirteen major bacterial taxa (each represented by $>0.5 \%$ of total sequences) were exclusively found in the CAP of the fresh rumen fluid, and 11 of those taxa were also found to be CAP-specific in the Ent. caudatum and the Epi. caudatum monocultures (Figure 4). These "common" CAPspecific bacterial sequences were found in at least $75 \%$ of the replicated CAP samples and were not detected at all in the FLP. Sediminibacterium, two different families of $\alpha$-Proteobacteria, unclassified $\beta$-Proteobacteria, and unclassified Acidimicrobiales were shared by $90 \%$ of all CAP samples of both monocultures of Ent. caudatum and Epi. caudatum and the CAP of the fresh rumen fluid.

\section{Methanogens}

Collectively, methanogens belonging to the genera Methanobrevibacter and Methanimicrococcus and the class of Thermoplasmata were identified from the FLP of rumen fluid and the CAP of the fresh rumen fluid (Table 3B). Among all the 72 analyzed single ciliate cells of fresh rumen fluid, only 32 had one or more methanogen taxa detected, with 25 of the 72 CAP samples having detectable Methanobrevibacter, 8 having Thermoplasmata, and 1 having only Methanimicrococcus that was not detected in the FLP (a few CAP samples had more than one of the methanogen taxa detected). No significant difference in the relative abundance of each of the detected methanogen taxa was found among the 8 ciliate genera, between the CAP and the FLP, or among the five cows.

The qPCR analysis revealed the presence of Thermoplasmata in all the CAP and the FLP samples and the presence of Methanosphaera stadtmanae in the CAP of 4 of the 8 ciliate genera and the FLP of all the rumen fluid samples (Table 6). The relative abundance of total methanogens was higher in the FLP than in the CAP of all the identified ciliate genera $(P<0.001)$ except Epidinium and Isotricha. The relative abundance of the other 3 methanogen taxa did not differ between the FLP and the CAP of any of the 8 ciliate genera. 
TABLE 3 | Relative abundance (\%) of methanogen taxa in the FLP and the CAP of the monocultures of Ent. caudatum and Epi. caudatum (A) and the fresh isolates of ruminal ciliates $\mathbf{( B )}{ }^{*}$.

\begin{tabular}{|c|c|c|c|c|c|c|c|c|c|c|c|c|}
\hline (A) & & & & & & & & & & & & \\
\hline \multirow[b]{2}{*}{ Taxa } & \multicolumn{6}{|c|}{ Ent. caudatum } & \multicolumn{6}{|c|}{ Epi. caudatum } \\
\hline & FLP & CAP & SEM & Fraction & Time & $F^{\star} T$ & FLP & CAP & SEM & Fraction & Time & $F^{*} \mathbf{T}$ \\
\hline Methanobrevibacter & 0.51 & 0.14 & 0.07 & 0.01 & 0.08 & 0.21 & 0.47 & 0.26 & 0.11 & 0.42 & 0.95 & 0.89 \\
\hline Methanosphaera & 0.03 & 0 & 0.01 & 0.18 & 0.58 & 0.58 & 0.03 & 0 & 0.01 & 0.18 & 0.58 & 0.58 \\
\hline Thermoplasmata & 0.31 & 0.08 & 0.07 & 0.12 & 0.61 & 0.71 & 0.35 & 0.35 & 0.08 & 1.00 & 0.52 & 0.61 \\
\hline
\end{tabular}

CAP of individual ruminal ciliate genera

FLP SEM samples

No. of

detected

\begin{tabular}{|c|c|c|c|c|c|c|c|c|c|c|c|}
\hline Taxa & Dasytricha & Diplodinium & Diploplastron & Entodinium & Epidinium & Isotricha & Ophryoscolex F & olyplastron & & & \\
\hline Methanobrevibacter & 0.12 & 0.04 & 0.57 & 0.22 & 0.73 & 0.21 & 0.56 & 0.10 & 0.30 & 0.07 & $25 / 72$ \\
\hline Methanimicrococcus & 0 & 0 & 0.56 & 0 & 0 & 0 & 0 & 0 & 0 & 0.07 & $1 / 72$ \\
\hline Thermoplasmata & 0.01 & 0 & 0.09 & 0.14 & 0.10 & 0.10 & 0 & 0.26 & 0.11 & 0.04 & $8 / 72$ \\
\hline Overall & 0.13 & 0.04 & 1.22 & 0.36 & 0.83 & 0.31 & 0.56 & 0.37 & 0.41 & 0.10 & $32 / 72$ \\
\hline
\end{tabular}

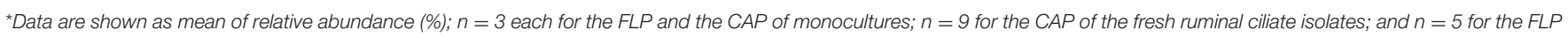
of the rumen fluid sample.

TABLE 4 | Relative abundance (\%) of methanogenic taxa in the monocultures of Ent. caudatum and Epi. caudatum as quantified using qPCR.

\begin{tabular}{|c|c|c|c|c|c|c|c|c|c|c|c|c|}
\hline & \multicolumn{4}{|c|}{ FLP } & \multicolumn{4}{|c|}{ CAP } & \multirow{2}{*}{ SEM } & \multicolumn{3}{|c|}{$P$-value } \\
\hline & $\mathrm{Oh}$ & $2 \mathrm{~h}$ & $4 \mathrm{~h}$ & $8 \mathrm{~h}$ & $\mathrm{Oh}$ & $2 \mathrm{~h}$ & $4 \mathrm{~h}$ & $8 \mathrm{~h}$ & & Fraction & Time & $F^{\star} T$ \\
\hline Total archaea & 0.283 & 0.326 & 0.346 & 0.303 & 0.203 & 0.194 & 0.396 & 0.144 & 0.028 & 0.151 & 0.251 & 0.536 \\
\hline Methanobrevibacter & 0.110 & 0.118 & 0.140 & 0.141 & 0.191 & 0.210 & 0.304 & $<0.001$ & 0.026 & 0.323 & 0.209 & 0.175 \\
\hline \multicolumn{13}{|l|}{ Epi. caudatum } \\
\hline Total archaea & 0.314 & 0.410 & 0.352 & 0.262 & 0.191 & 0.093 & 0.084 & 0.066 & 0.041 & 0.008 & 0.819 & 0.812 \\
\hline Methanobrevibacter & 0.131 & 0.117 & 0.118 & 0.077 & 0.196 & 0.021 & 0.023 & 0.003 & 0.019 & 0.163 & 0.093 & 0.307 \\
\hline Thermoplasmata & 0.108 & 0.155 & 0.105 & 0.068 & 0.011 & 0.052 & 0.074 & 0.056 & 0.012 & 0.010 & 0.386 & 0.326 \\
\hline M. stadtmanae ${ }^{\#}$ & 0.146 & 0.256 & 0.056 & 0.050 & $<0.001$ & 0 & $<0.001$ & 0 & 0.032 & 0.061 & 0.630 & 0.630 \\
\hline
\end{tabular}

${ }^{*}$ Data are shown as means $(n=3)$ of relative abundance of individual taxa relative to total prokaryotes.

\# Methanosphaera stadtmanae.

\section{DISCUSSION}

Living in the rumen where prokaryotes exist constantly at a very high density, at least $10^{10}$ bacteria per $\mathrm{g}$ of rumen content (calculated from Yu and Morrison, 2004; Kim and $\mathrm{Yu}, 2012$ ) ruminal ciliates have the opulence of bacteria and archaea to choose as preys or symbiotic partners. During the evolution of ruminants over millions of years (Mackie, 2002), ruminal ciliates and other members of the ruminal microbiota, especially the prokaryotes, formed intriguing predator-prey and symbiotic relationships. Using highthroughput sequencing, this study represents the first effort to investigate the potential selectivity of ruminal ciliates toward preys and symbiotic partners. Certain bacteria, but not methanogenic archaea, appeared to be associated with ciliate cells, either enriched or exclusively found in ruminal ciliate cells. Those bacteria enriched in the ruminal ciliate cells may represent the preferred preys, while those exclusively found in the ruminal ciliate cells are probably symbionts.

\section{Differential Prokaryotic Populations Inside and Outside of Ruminal Ciliates}

The two ciliate monocultures had very different FLP, but rather similar CAP (Figure 1A). Because the two monocultures were fed the same feed but grown in different media, the difference 

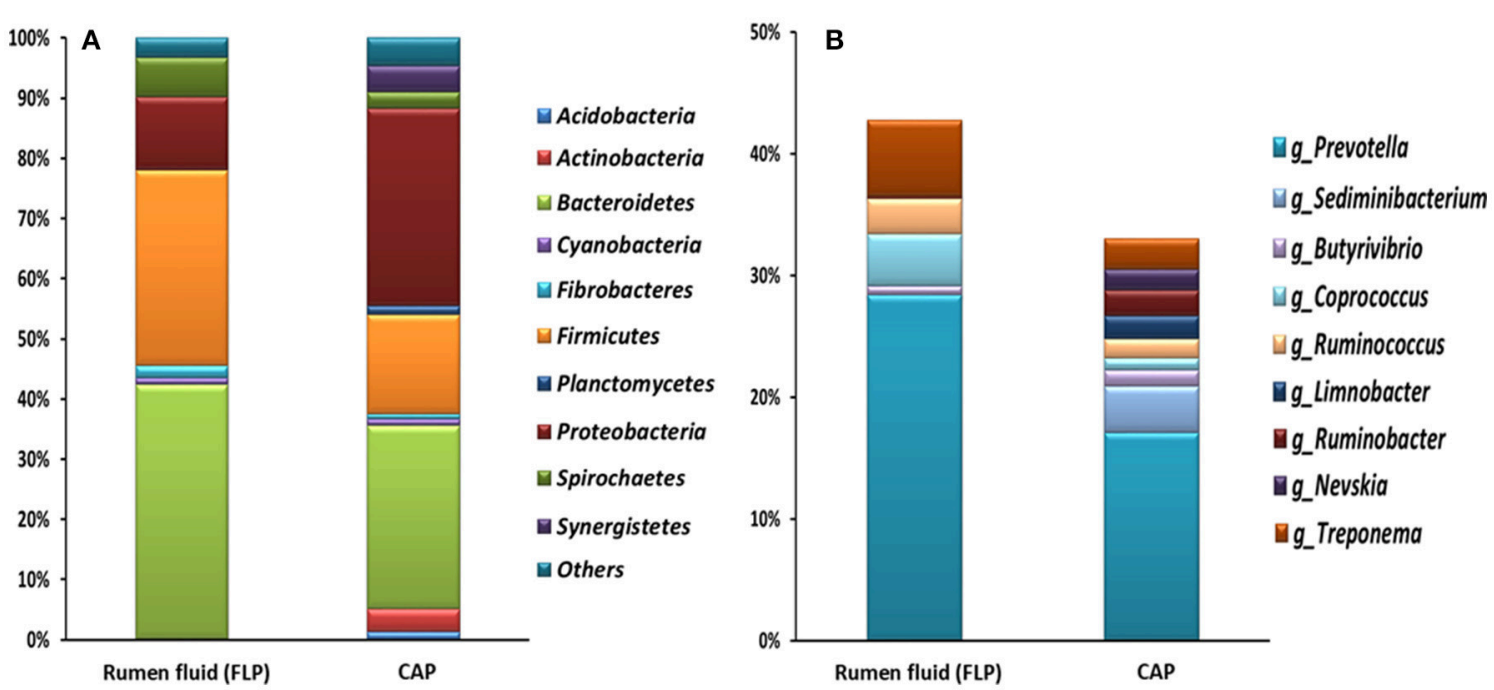

FIGURE 5 | Relative abundance of major bacterial phyla (A) and genera (B) (each representing $>1 \%$ of total sequences) of the CAP of freshly isolated ruminal ciliate single cells (average of 8 genera) and the FLP of the rumen fluid collected from Jersey dairy cows. Relative abundance of the genera did not add up to $100 \%$ because unclassified bacterial taxa were not included.

in the FLP and similarity in the CAP between the two ciliate species may suggest selectivity for prokaryotes either as preys or as symbionts. The small difference in the CAP between the two ciliate species might suggest different selectivity. Entodinium has smaller cell size than Epidinium and prefers small-sized starch granules (Williams and Coleman, 1997). It is conceivable that Entodinium selects small prokaryotic cells as preys due to its small size. Entodinium also has greater bacterivorous activity than other rumen ciliates (Coleman G. S. and Sandford, 1979). It remains to be determined if and to what extent the above morphological and behavioral differences contribute to prey preference and selection. It is also interesting to note that the profiles of the CAP-specific bacteria were rather stable overtime after feeding even though both ciliate species were incubated as batch monocultures. This suggests that the bacteria associated with each ciliate species are relatively stable and our single cell procedure can generate rather reproducible CAP profiles.

As shown in the ciliate monocultures, the FLP of the rumen fluid had greater species richness and diversity than the CAP. Compared to the FLP of the monocultures of Ent. caudatum and Epi. caudatum, the FLP of the rumen fluid had a much greater species richness and diversity (Table 1) but a lower predominance of Proteobacteria (Figure 3). The predominance of Proteobacteria, particularly $\gamma$-Proteobacteria, in the FLP of the monocultures, which was fed a wheat-based ciliate feed, is consistent with the increased occurrence of $\gamma$-Proteobacteria in the rumen of cattle fed a high grain diet (Petri et al., 2013). Interestingly, the CAP of the fresh rumen fluid also had a similar relative abundance of Proteobacteria as the CAP of the in vitro monocultures of Ent. caudatum and Epi. caudatum, and $\alpha$-Proteobacteria was also detected as the most predominant class of CAP-specific bacteria (on average, over $14 \%$ of the CAP-specific bacteria were assigned to this class among all isolates). Evidently, ruminal ciliates prefer some members of Proteobacteria, especially $\alpha$-Proteobacteria, as preys or symbiotic partners even when living in the presence of different FLP. This is another line of evidence for selective predation and/or symbiosis of ruminal ciliates. The finding of Proteobacteria as predominant CAP of the ruminal ciliates is consistent with this group of bacteria being predominant inside free-living ciliates (Görtz and Brigge, 1998). However, our results contradict the report of Irbis and Ushida (2004), who detected Firmicutes as the dominant bacteria (87.2\%) followed by Bacteroidetes (10.6\%). Future research is needed to determine if Proteobacteria is the preferred prey or endosymbionts of ruminal ciliates.

\section{Bacteria Enriched in Ruminal Ciliate-Associated Prokaryotes}

Selective predation has been demonstrated in fresh-living freshwater zooplankton, some nonflagellates, and ciliates, and the selectivity was attributed to size selection of the preys (Greene, 1983; Kinner et al., 1998; Matz and Kjelleberg, 2005). By comparing the overall rumen microbiotas between faunated and defaunated ruminants (Ushida et al., 1991; Ozutsumi et al., 2006), selective predation was also suggested for ruminal ciliates. In the present study, we found that some bacteria were significantly "enriched" in the CAP though they were also found in the FLP. The enriched bacteria were assigned to a small number of taxa including Actinobacteria, Butyrivibrio, Proteobacteria, $\beta$ Proteobacteria, Burkholderiales, and Moraxellaceae. Interestingly, similar enriched bacteria were found in the CAP of both monocultures maintained in laboratory and the fresh rumen fluid, and this congruence between laboratory monocultures 
TABLE 5 | Relative abundances (\%) of major known bacterial taxa* in the FLP and the CAP of freshly isolated ruminal ciliates.

\begin{tabular}{|c|c|c|c|c|c|c|c|c|c|c|c|c|}
\hline \multirow{3}{*}{$\begin{array}{l}\text { Phylum } \\
\text { Lowest taxa } \\
\text { assigned }^{\star \star}\end{array}$} & \multirow{2}{*}{\multicolumn{8}{|c|}{ CAP of individual ciliate genera }} & \multirow{3}{*}{ FLP } & \multirow{2}{*}{\multicolumn{3}{|c|}{$P$-value }} \\
\hline & & & & & & & & & & & & \\
\hline & Dasytricha & Diplodinium & Diploplastron & Entodinium & Epidinium & Isotricha & Ophryoscolex & Polyplastron & & Genera & $\begin{array}{c}\text { CAP } \\
\text { vs. FLP }\end{array}$ & $\begin{array}{c}\text { Detection } \\
\text { in CAP }\end{array}$ \\
\hline Acidobacteria & 1.72 & 1.86 & 1.48 & 1.38 & 1.03 & 0.92 & 0.98 & 1.68 & 0 & NS & 0.048 & Only \\
\hline Actinobacteria & 4.71 & 4.09 & 3.77 & 3.25 & 2.32 & 3.59 & 5.79 & 2.37 & 0.08 & NS & 0.021 & Enriched \\
\hline o_Acidimicrobiales & 3.41 & 3.58 & 3.49 & 3.16 & 1.98 & 2.84 & 4.12 & 1.66 & 0 & NS & NS & Only \\
\hline Bacteroidetes & 30.9 & 28.6 & 35.2 & 29.1 & 33.4 & 31.2 & 30.2 & 25.5 & 42.4 & NS & 0.003 & \\
\hline c_Bacteroidia & 25.9 & 23.8 & 30.2 & 24.8 & 29.2 & 26.1 & 24.3 & 23.1 & 42.4 & NS & 0.048 & \\
\hline$f \_B S 11$ & 2.03 & 1.15 & 1.47 & 2.19 & 1.43 & 1.19 & 0.81 & 1.43 & 0.05 & NS & 0.040 & Enriched \\
\hline g_Prevotella ${ }^{\dagger}$ & 15.9 & 14.3 & 21.5 & 15.8 & 19.7 & 18.6 & 16.6 & 14.4 & 28.4 & NS & $<0.001$ & \\
\hline f_Paraprevotellaceae & 0.76 & 0.92 & 1.62 & 0.89 & 1.33 & 1.52 & 1.55 & 1.68 & 4.96 & NS & NS & \\
\hline f_Chitinophagaceae & 4.90 & 3.94 & 4.04 & 4.25 & 4.05 & 4.84 & 5.10 & 2.15 & 0 & 0.057 & NS & Only \\
\hline g_Sediminibacterium & 4.78 & 3.63 & 3.62 & 3.53 & 3.54 & 4.22 & 4.70 & 2.14 & 0 & NS & 0.032 & Only \\
\hline Cyanobacteria & 2.81 & 0.82 & 0.59 & 1.37 & 0.37 & 0.68 & 1.29 & 0.50 & 1.09 & NS & NS & \\
\hline Fibrobacteres & 1.93 & 0.32 & 0.78 & 0.34 & 1.01 & 0.48 & 1.21 & 0.31 & 2.08 & NS & NS & \\
\hline Firmicutes & 16.2 & 17.9 & 15.9 & 13.1 & 18.5 & 19.8 & 15.0 & 16.3 & 32.4 & NS & $<0.001$ & \\
\hline o_Clostridiales & 14.9 & 16.6 & 14.9 & 12.0 & 15.9 & 19.2 & 13.3 & 15.2 & 30.5 & 0.071 & $<0.001$ & \\
\hline f_Lachnospiraceae & 8.57 & 8.51 & 6.79 & 6.87 & 7.75 & 14.8 & 7.12 & 6.71 & 17.4 & NS & 0.032 & \\
\hline g_Butyrivibrio & 1.89 & 1.54 & 0.73 & 1.59 & 1.58 & 1.32 & 1.62 & 0.38 & 0.74 & 0.011 & $<0.001$ & Enriched \\
\hline g_Coprococcus & 0.77 & 0.94 & 0.93 & 1.28 & 1.44 & 0.38 & 0.90 & 1.15 & 4.26 & NS & 0.054 & \\
\hline f_Ruminococcaceae & 2.73 & 3.41 & 3.78 & 1.82 & 3.23 & 1.69 & 2.29 & 3.62 & 4.82 & NS & $<0.001$ & \\
\hline g_Ruminococcus & 1.80 & 1.12 & 2.59 & 1.36 & 1.85 & 0.98 & 1.07 & 2.20 & 2.93 & NS & NS & \\
\hline f_Veillonellaceae & 1.63 & 2.01 & 1.01 & 0.57 & 1.74 & 1.42 & 1.35 & 1.98 & 0.85 & NS & 0.095 & \\
\hline Planctomycetes & 1.57 & 2.07 & 2.20 & 1.16 & 1.59 & 0.87 & 1.11 & 1.30 & 0.02 & NS & NS & \\
\hline Proteobacteria & 31.4 & 35.9 & 24.2 & 34.3 & 33.2 & 29.8 & 29.9 & 43.9 & 12.2 & 0.071 & $<0.001$ & Enriched \\
\hline c_ $\alpha$-Proteobacteria & 7.57 & 7.80 & 4.52 & 6.14 & 7.75 & 5.41 & 5.96 & 13.1 & 0.63 & NS & 0.021 & \\
\hline o_Ellin329 & 2.34 & 1.57 & 1.00 & 1.84 & 2.86 & 1.20 & 1.71 & 2.20 & 0 & 0.035 & 0.005 & Only \\
\hline o_Rhizobiales & 1.36 & 2.23 & 1.37 & 1.06 & 1.36 & 1.65 & 1.74 & 1.71 & 0 & NS & NS & Only \\
\hline f_Bradyrhizobiaceae & 1.09 & 1.43 & 0.91 & 0.85 & 0.69 & 1.46 & 1.29 & 1.45 & 0 & NS & 0.036 & $\overline{\text { Only }}$ \\
\hline$f \_R h o d o s p i r i l l a c e a e^{\dagger}$ & 2.88 & 3.60 & 1.26 & 1.90 & 2.27 & 2.08 & 1.88 & 1.60 & 0 & NS & 0.020 & Only \\
\hline c_ $\beta$-Proteobacteria & 5.22 & 6.24 & 5.37 & 3.80 & 5.04 & 6.90 & 7.27 & 5.39 & 0.08 & NS & 0.003 & Enriched \\
\hline o_Burkholderiales & 2.66 & 3.85 & 2.83 & 2.16 & 2.80 & 4.66 & 2.91 & 4.09 & 0.08 & NS & $<0.001$ & Enriched \\
\hline g_Limnobacter & 1.51 & 2.51 & 2.06 & 1.01 & 1.77 & 2.84 & 1.68 & 1.71 & 0 & NS & 0.054 & Only \\
\hline c_ $\delta$-Proteobacteria & 1.66 & 2.83 & 2.91 & 2.51 & 2.40 & 3.09 & 2.38 & 3.14 & 0.09 & NS & NS & \\
\hline c_E-Proteobacteria & 1.88 & 1.37 & 1.96 & 2.94 & 1.43 & 0.33 & 0.79 & 1.55 & 0 & NS & NS & Only \\
\hline c_ $\gamma$-Proteobacteria & 15.1 & 17.7 & 9.45 & 18.9 & 16.6 & 14.1 & 13.5 & 20.8 & 11.4 & NS & $<0.001$ & Enriched \\
\hline & 7.12 & 9.76 & 5.30 & 9.02 & 8.37 & 6.43 & 6.58 & 16.0 & 11.3 & NS & 0.036 & \\
\hline f_Succinivibrionaceae ${ }^{\dagger}$ & & & & & & & & & & & & \\
\hline g_Ruminobacter & 2.24 & 2.38 & 1.11 & 2.03 & 3.18 & 2.24 & 1.51 & 2.19 & 0.19 & NS & 0.020 & Enriched \\
\hline o_Pseudomonadales & 1.96 & 2.12 & 0.96 & 2.88 & 1.72 & 2.66 & 1.58 & 1.87 & 0.02 & 0.083 & 0.013 & Enriched \\
\hline f_Moraxellaceae & 1.60 & 1.74 & 0.35 & 1.95 & 0.90 & 1.07 & 1.15 & 1.58 & 0.02 & NS & 0.051 & Enriched \\
\hline o_Xanthomonadales & 4.36 & 3.52 & 2.26 & 5.55 & 3.66 & 3.11 & 3.81 & 1.65 & 0 & NS & 0.008 & Only \\
\hline f_Sinobacteraceae & 4.25 & 2.56 & 1.92 & 4.77 & 3.10 & 2.97 & 3.64 & 1.53 & 0 & NS & 0.042 & $\overline{\text { Only }}$ \\
\hline g_Nevskia & 2.74 & 1.56 & 1.36 & 2.29 & 1.41 & 1.55 & 1.49 & 1.06 & 0 & 0.067 & NS & Only \\
\hline Spirochaetes & 2.90 & 1.73 & 5.69 & 2.80 & 1.12 & 3.02 & 1.89 & 2.35 & 6.45 & 0.035 & 0.005 & \\
\hline g_Treponema ${ }^{\dagger}$ & 2.73 & 1.73 & 5.46 & 2.73 & 0.96 & 2.66 & 1.89 & 1.99 & 6.26 & NS & NS & \\
\hline Synergistetes & 2.33 & 3.61 & 5.94 & 9.70 & 2.11 & 1.99 & 5.76 & 2.80 & 0.02 & NS & NS & \\
\hline
\end{tabular}

${ }^{\star}$ Only the taxa over a relative abundance greater than $1 \%$ were shown.

${ }^{\star *}$ C, Class; o, Order; f, Family; g, Genus.

\#Found only in the CAP. Those taxa exclusively found in the CAP of the in vitro monocultures of Ent. caudatum and Epi. caudatum are underlined.

${ }^{\dagger}$ For those taxa, only the lowest classifiable taxa were shown because their higher taxa had similar relative abundance as the taxa shown.

and fresh isolates shall not be regarded as chance. Little is known about the selective predation of ruminal ciliates, and several studies done in the 1980's and 1990's showed that Butyrivibrio fibrisolvens and Selenomonas ruminantium were probably preferred preys for various ruminal ciliates (Coleman,
1964, 1986; Coleman and Laurie, 1974, 1977; Coleman G. and Sandford, 1979; Coleman G. S. and Sandford, 1979). In a few later studies (Coleman G. S. and Sandford, 1979; De la Fuente et al., 2011), however, several species of the entodiniomorphs (ex: Ent. caudatum, Diplodinium dentatum, and Metadinium 
TABLE 6 | Relative abundance (\%) of methanogenic taxa in both FLP and CAP of freshly isolated ruminal ciliate cells as quantified using qPCR*.

\begin{tabular}{|c|c|c|c|c|c|c|c|c|c|c|c|}
\hline \multirow[b]{2}{*}{ Taxa } & \multicolumn{8}{|c|}{ CAP of individual ruminal ciliate genera } & \multirow[b]{2}{*}{ FLP } & \multicolumn{2}{|c|}{$P$-value } \\
\hline & Dasytricha & Diplodinium & Diploplastron & Entodinium & Epidinium & Isotricha & Ophryoscolex & Polyplastron & & Genera & $\begin{array}{c}\text { CAP } \\
\text { vs. FLP }\end{array}$ \\
\hline Total methanogens & $0.153^{b}$ & $0.164^{b}$ & $0.135^{b}$ & $0.160^{b}$ & $0.251^{\mathrm{ab}}$ & $0.416^{a b}$ & $0.212^{b}$ & $0.166^{b}$ & $0.891^{a}$ & 0.359 & $<0.001$ \\
\hline Methanobrevibacter & 0.104 & 0.112 & 0.071 & 0.052 & 0.166 & 0.104 & 0.160 & 0.041 & 0.260 & 0.300 & $<0.001$ \\
\hline Thermoplasmata & 0.035 & 0.103 & 0.014 & 0.013 & 0.019 & 0.193 & 0.110 & 0.055 & 0.335 & 0.520 & $<0.001$ \\
\hline M. stadtmanae \# & 0.022 & $<0.001$ & $<0.001$ & 0.100 & 0.054 & $<0.001$ & $<0.001$ & 0.067 & 0.018 & 0.229 & 0.666 \\
\hline
\end{tabular}

*Data are shown as means of relative abundance of individual taxa relative to total prokaryotes. $n=9$ for CAP of each ciliate genus and $n=5$ for FLP.

\#Methanosphaera stadtmanae.

Different superscripts within a row indicate significant differences $(P<0.05)$.

medium) showed no preference in engulfing the tested bacterial species. Additionally, Butyrivibrio and several taxa of Proteobacteria were differently enriched among the different genera of the ruminal ciliates, suggesting different selectivity or preference of ruminal bacteria as preys. Collectively, the present study provided new evidence to pointing toward selective predation of ruminal bacteria by ruminal ciliates. Further studies using different approaches, such as using labeled bacteria, can help confirm selected predation and elucidate the underlying mechanism.

\section{Bacteria Exclusively Found in Ruminal Ciliate-Associated Prokaryotes}

A number of bacterial taxa were only found in the CAP of both the laboratory ciliate monocultures and the fresh rumen fluid. Most of these "CAP-specific" bacteria belong to Proteobacteria (further discussed below). Some of the CAP-specific bacteria, including those classified to Acidobacteria, Actinobacteria, and Sediminibacterium, are common soil bacteria, but they were considered allochthonous, not autochthonous, in the rumen $(\mathrm{Qu}$ and Yuan, 2008; Henderson et al., 2015). The high prevalence and predominance of these bacteria exclusively found in the CAP of both ciliate monocultures and the fresh rumen fluid identified in the present study cannot be simply explained as contamination because they were not detected in the FLP.

Free-living ciliates can acquire endosymbiotic prokaryotes by vertical transmission and direct recruitment. Vertical transmission of methanogenic endosymbionts from one generation to the next has been reported in freshwater ciliates, such as species of Metopus, Brachonella, Caenomorpha, and intestinal (not ruminal) ciliates, such as Nyctotherus ovalis of cockroach (van Hoek et al., 2000). The vertically transmitted endosymbionts are often undetectable in FLP fraction (van Hoek et al., 2000). Direct recruitment of endosymbionts has been shown in anaerobic heterotrichous ciliates Nyctotherus spp. (van Hoek et al., 1999, 2000), and the directly recruited endosymbionts can be found in both FLP and CAP fractions. Also, replacement of endosymbiotic methanogens was reported in the monoxenic culture of Trimyema compressum, a free-living anaerobic ciliate, with the initial endosymbiotic bacteria (mostly Firmicutes) and methanogens (Methanobacteriaceae) being successfully replaced with Methanobacterium formicicum as its new endosymbionts (Wagener et al., 1990). The above acquisition mechanisms of both bacterial and archaeal endosymbionts were determined from research on diverse free-living non-ruminal ciliates. In the rumen, prokaryotes exist at a greater abundance $\left(10^{10}-10^{11} / \mathrm{g}\right.$ of rumen content) and population stability than in other environments, such as marine $\left(10^{6}\right.$ cells $\left./ \mathrm{ml}\right)$ (Amaral-Zettler et al., 2010) and freshwater $\left(10^{5}-10^{7}\right.$ cells $/ \mathrm{ml}$ ) (White et al., 1991). The persistent high density of prokaryotes together with the vigorous bacterivorous activity of ruminal ciliates (Coleman G. S. and Sandford, 1979; De la Fuente et al., 2011) would make multiple acquisitions of free-living prokaryotes as endosymbionts more plausible in the rumen than in other habitats. However, the significant differences between the CAP and the FLP of both the in vitro monocultures and the fresh ruminal samples analyzed in the present study suggest possible vertical transmission. Moreover, the similar CAP-specific taxa found from the in vitro monocultures of Ent. caudatum and Epi. caudatum and from the single ciliate cells of fresh rumen fluid also suggest vertical transmission of endosymbionts. Specifically, the CAP-specific bacteria, especially those of Proteobacteria including $\alpha$ - and $\beta$-Proteobacteria, which are minor ruminal bacteria, were ubiquitous in all the CAP samples. In addition to their omnipresence in the CAP, rare detection of CAP-specific bacteria in the FLP supports the argument of their vertical transmission as endosymbionts. Analysis using FISH has detected prokaryotic cells outside food vacuoles but underneath the pellicle of some ruminal ciliates including Ent. caudatum (Valle et al., 2015), and intracellular replicating prokaryotic cells were also observed through transmission electron microscopy (Park et al., 2017), lending support to the presence of true endosymbionts of ruminal ciliates.

$\alpha$-Proteobacteria were detected at high predominance in the CAP-specific bacteria (13.4\% of the CAP of Ent. caudatum, $7.40 \%$ of the CAP of Epi. caudatum, and $5.17 \%$ of the CAP among the fresh isolates). $\alpha$-Proteobacteria can resist digestion inside ciliate cells (Gong et al., 2016), and the mechanisms have been investigated, mostly in free-living ciliates (Görtz, 2001). It was speculated that some $\alpha$-Proteobacteria can express certain periplasmic proteins, which can interact with phagosomal membranes or provide protection from lysis by inactivating host lytic enzymes. Indeed, certain bacteria have inherent phospholipid metabolism and protein secretion systems that afford resistance to digestion by ciliates and intra-ciliate survival 
by translocating effector proteins (Hubber et al., 2004; Lutz et al., 2015). Additionally, among the $\alpha$ - and $\gamma$-Proteobacteria associated with protists, types 6 and 4 secretion systems are known to allow them to survive inside ciliate host cells (Christie and Cascales, 2005; Pukatzki et al., 2006). Furthermore, coding genes of three types of lysozyme inhibitors have been found in the completed genomes of some $\alpha$-, $\beta$-, and $\gamma$-Proteobacteria (Callewaert et al., 2012), and these bacteria were predominant in the CAP of both Ent. caudatum and Epi. caudatum. Therefore, the high predominance of Proteobacteria, particularly $\alpha$-Proteobacteria, among the CAP-specific bacteria could be attributable to their resistance to digestion and/or their ability to replicate inside the ruminal ciliate cells (Gong et al., 2016).

Devosia was among the minor taxa $(<0.5 \%$ of total prokaryotes) of the CAP-specific bacteria. This genus belongs to $\alpha$-Proteobacteria, and it contains the second obligate endosymbiont ever isolated from ciliate Euplotes magicirratus (Vannini et al., 2003). However, Euplotes magicirratus has never been detected in the rumen, and thus the occurrence of Devosia exclusively in the CAP of the single ruminal ciliate cells was intriguing. In our previous study (Park et al., 2017) and several other studies (Coleman, 1962; Hino and Kametaka, 1977; Bonhomme et al., 1982a,b), it was demonstrated that Ent. caudatum could not be grown or maintained in axenic cultures. Presumably, the antibiotics used to remove the freeliving bacteria also killed the intracellular prokaryotes that are essential for the survival of host ciliates, as in the case where Euplotes depends on Devosia for survival (Vannini et al., 2003). Further research is warranted to determine if the intracellular prokaryotes detected in our study, particularly the members of Proteobacteria including Devosia-related bacteria are essential endosymbionts for the survival of host ciliates. Endosymbionts, including obligate endosymbionts, such as Polynucleobacter, have been reported for several species of ciliates (Soldo, 1987; Görtz, 2001). No endosymbionts have ever been reported for ruminal ciliates. Given that Ent. caudatum requires live prokaryotes for its survival (Fondevila and Dehority, 2001; Park et al., 2017), and repeated efforts have all failed to establish lasting axenic culture of ruminal ciliates (Coleman, 1962; Hino and Kametaka, 1977; Bonhomme et al., 1982a,b), it is tempting to speculate that certain species of these CAP-specific bacteria, especially those assigned to $\alpha$-Proteobacteria, such as Ellin329, Bradyrhizobiaceae and Rhodospirillaceae, might be the essential prokaryotes for ruminal ciliates, at least Ent. caudatum, to survive.

\section{Association of Methanogens With Ruminal Ciliate Cells}

Ruminal ciliates and methanogens (almost exclusively hydrogenotrophic methanogens) form mutualistic relationship via interspecies hydrogen transfer. This relationship contributes to methane production by rumen microbiome and thus has been a research focus. In the present study, methanogens were found at low relative abundance (of total prokaryotes), and no methanogen was enriched or found exclusively in the CAP of laboratory ciliate monocultures or the fresh rumen fluid, suggesting that the ruminal ciliates probably have no preference for methanogens as preys or vertically transmitted methanogenic endosymbionts. The methanogens detected in the CAP might be preys engulfed by the host ciliates. A couple of studies showed that only $8-40 \%$ the Entodinium cells examined had intracellular methanogens detectable (Vogels et al., 1980). Although at a higher frequency, other entodiniomorphids genera also did not have persistent detectable intracellular methanogens (Lloyd et al., 1996; Váradyová et al., 2001). Based on the results of the present study and previous studies (Finlay et al., 1994; Lloyd et al., 1996), ruminal ciliates probably do not have true persistent symbiotic methanogens or preference of methanogens as prey.

Endosymbionts have been reported surrounding hydrogenosomes of several anaerobic ciliates (Finlay et al., 1993; Shinzato et al., 2007). Such proximity can benefit both the ciliate host and the endosymbiotic methanogens. Among the ruminal ciliates analyzed in the present study, species of Ent. caudatum, Entodinium simplex (probably other species of Entodinium), and Diploplastron affine (probably other species of Diploplastron) contain no hydrogenosome, while species of Epidinium and other genera do have hydrogenosomes (Yarlett et al., 1984; Ellis et al., 1994). Hypothetically, the hydrogenosomes of Epi. caudatum and other genera can attract hydrogenotrophic methanogens as endosymbionts to consume the hydrogen released from the hydrogenosomes. In one study, production of hydrogen and/or formate increased after feeding, and free-living methanogens were attracted to the cytoplasm of ruminal ciliates (Tokura et al., 1997; Ushida, 2010). However, the relative abundance of Methanobrevibacter spp. in the CAP of Epi. caudatum decreased $2 \mathrm{~h}$ after feeding. In the present study, no difference was found in the occurrence or predominance of methanogens between the ruminal ciliates that contain hydrogenosomes and those contain no hydrogenosomes. Taken together, it is difficult to conclude if the detected methanogens are symbionts or engulfed preys. More research will be needed to verify the dynamic localization of methanogens associated with ruminal ciliates, especially hydrogenosome-carrying ciliates including Epi. caudatum and species of Isotricha and Dasytricha.

\section{CONCLUSION}

Technical limitations make it extremely difficult to identify true symbionts, to distinguish true endosymbionts from engulfed preys, or to determine the selectivity of symbionts and preys. Using both monocultures maintained in laboratory and fresh rumen fluid, we identified bacteria, not methanogens, enriched or exclusively found in extensively washed single cells of ruminal ciliates. These results suggest selective predation on bacteria by ruminal ciliates and the presence of symbionts, including possible vertical transmission of symbionts. Future studies can incorporate controlled starvation of ciliates and live-dead cells detection of CAP, such as treatment of washed 
ciliate cells with propidium monoazide, which penetrates into cells with damaged cell membrane and render their DNA unamplifiable by PCR (Nocker et al., 2007), to help distinguish symbionts from engulfed preys that have damaged cell membrane. Additionally, the CAP-specific bacteria can be specifically targeted for detection and localization using specific probes designed from the $16 \mathrm{~S}$ rRNA sequences, for characterization using single-cell genomics, or for isolation using new media designed from genomic information. Such studies can help elucidate the biological interactions between ciliates and prokaryotes and their role in rumen functions.

\section{AUTHOR CONTRIBUTIONS}

TP was responsible for the overall study including sample collection, data analysis and drafting the manuscript. ZY supervised the study and revised the paper.

\section{REFERENCES}

Amaral-Zettler, L., Artigas, L. F., Baross, J., Bharathi, L., Boetius, A., Chandramohan, D., et al. (2010). "A global census of marine microbes," in Life in the World's Oceans: Diversity, Distribution and Abundance ed A. McIntyre (Oxford: Blackwell Publishing Ltd.), 223-245.

Baraka, T. (2012). Comparative studies of rumen PH, total protozoa count, generic and species composition of ciliates in camel, buffalo, cattle, sheep and goat in Egypt. J. Am. Sci. 8, 655-669. doi: 10.5564/mjas.v19i3.730

Belanche, A., Abecia, L., Holtrop, G., Guada, J., Castrillo, C., De La Fuente, G., et al. (2011). Study of the effect of presence or absence of protozoa on rumen fermentation and microbial protein contribution to the chyme 1. J. Anim. Sci. 89, 4163-4174. doi: 10.2527/jas.2010-3703

Belanche, A., De La Fuente, G., and Newbold, C. J. (2014). Study of methanogen communities associated with different rumen protozoal populations. FEMS Microbiol. Ecol. 90, 663-677. doi: 10.1111/1574-6941. 12423

Bonhomme, A., Durand, M., Quintana, C., and Halpern, S. (1982a). Influence du cobalt et de la vitamine B12 sur la croissance et la survie des ciliés du rumen in vitro, en fonction de la population bactérienne. Reprod. Nutr. Dévelop. 22, 107-122.

Bonhomme, A., Fonty, G., and Senaud, J. (1982b). Attempt to obtain and maintain rumen entodiniomorph ciliates in axenic cultures. Ann. Microbiol. 133, 335-341.

Callewaert, L., Van Herreweghe, J. M., Vanderkelen, L., Leysen, S., Voet, A., and Michiels, C. W. (2012). Guards of the great wall: bacterial lysozyme inhibitors. Trends Microbiol. 20, 501-510. doi: 10.1016/j.tim.2012.06.005

Caporaso, J. G., Kuczynski, J., Stombaugh, J., Bittinger, K., Bushman, F. D., Costello, E. K., et al. (2010). QIIME allows analysis of highthroughput community sequencing data. Nat. Methods 7, 335-336. doi: 10.1038/nmeth.f.303

Caporaso, J. G., Lauber, C. L., Walters, W. A., Berg-Lyons, D., Lozupone, C. A., Turnbaugh, P. J., et al. (2011). Global patterns of 16S rRNA diversity at a depth of millions of sequences per sample. Proc. Nat. Acad. Sci. U.S.A. 108, 4516-4522. doi: $10.1073 /$ pnas.1000080107

Chagan, I., Tokura, M., Jouany, J. P., and Ushida, K. (1999). Detection of methanogenic archaea associated with rumen ciliate protozoa. J. Gen. Appl. Microbiol. 45, 305-308. doi: 10.2323/jgam.45.305

Christie, P. J., and Cascales, E. (2005). Structural and dynamic properties of bacterial type IV secretion systems. Mol. Membr. Biol. 22, 51-61. doi: 10.1080/09687860500063316

Clarke, K. R., and Gorley, R. N. (2006). PRIMER V6: User Manual-Tutorial. Plymouth, UK: Plymouth Marine Laboratory.

\section{FUNDING}

This project is partially supported by the National Institute of Food and Agriculture, U.S. Department of Agriculture, under award number 2012-67015-19437.

\section{ACKNOWLEDGMENTS}

The authors thank Jeffrey L. Firkins for providing instrumental facilities to do the protozoal culturing. Microscopic imaging of the ciliate cells was aided by the Campus Microscopy \& Imaging Facility of The Ohio State University.

\section{SUPPLEMENTARY MATERIAL}

The Supplementary Material for this article can be found online at: https://www.frontiersin.org/articles/10.3389/fmicb. 2018.01710/full\#supplementary-material

Coleman, G. (1964). The metabolism of Escherichia coli and other bacteria by Entodinium caudatum. Microbiology 37, 209-223. doi: 10.1099/00221287-37-2-209

Coleman, G., and Laurie, J. I. (1974). The metabolism of starch, glucose, amino acids, purines, pyrimidines and bacteria by three and Epidinium spp. isolated from the rumen. Microbiology 85, 244-256. doi: 10.1099/00221287-85-2-244

Coleman, G., and Laurie, J. I. (1977). The metabolism of starch, glucose, amino acids, purines, pyrimidines and bacteria by the rumen ciliate Polyplastron multivesiculatum. Microbiology 98, 29-37. doi: 10.1099/00221287-98-1-29

Coleman, G. S. (1962). The preparation and survival of almost bacteriafree suspensions of Entodinium caudatum. J. Gen. Microbiol. 28, 271-281. doi: 10.1099/00221287-28-2-271

Coleman, G. S. (1986). The metabolism of rumen ciliate protozoa. FEMS Microbiol. Lett. 39, 321-344. doi: 10.1111/j.1574-6968.1986.tb01864.x

Coleman, G., and Sandford, D. C. (1979). The uptake and utilization of bacteria, amino acids and nucleic acid components by the rumen ciliate Eudiplodinium maggii. J. Appl. Microbiol. 47, 409-419.

Coleman, G. S., and Sandford, D. C. (1979). The engulfment and digestion of mixed rumen bacteria and individual bacterial species by single and mixed species of rumen ciliate protozoa grown in vivo. J. Agric. Sci. 92, 729-742. doi: 10.1017/S0021859600053971

Dehority, B. A. (1986). Protozoa of the digestive tract of herbivorous mammals. Int. J. Trop. Insect Sci. 7, 279-296. doi: 10.1017/S1742758400009346

Dehority, B. A. (1998). Generation times of Epidinium caudatum and Entodinium caudatum, determined in vitro by transferring at various time intervals. J. Anim. Sci. 76, 1189-1196. doi: 10.2527/1998.7641189x

Dehority, B. A. (2003). Rumen Microbiology. Nottingham: Nottingham University Press.

Dehority, B. A. (2005). "Ciliate protozoa," in Methods in Gut Microbial Ecology for Ruminants, eds H. P. S. Makkar and C. S. McSweeney (Dordrecht: Springer), 67-78.

Dehority, B. A. (2010). Physiological characteristics of several rumen protozoa grown in vitro with observations on within and among species variation. Eur. J. Protistol. 46, 271-279. doi: 10.1016/j.ejop.2010.05.002

De la Fuente, G., Fondevila, M., Belanche, A., and Morgavi, D. (2011). in vitro predation of pure bacterial species by rumen protozoa from monofaunated sheep, determined by qPCR. Options Mediterr. 99, 91-96.

DeSantis, T. Z., Hugenholtz, P., Larsen, N., Rojas, M., Brodie, E. L., Keller, K., et al. (2006). Greengenes, a chimera-checked 16S rRNA gene database and workbench compatible with ARB. Appl. Environ. Microbiol. 72, 5069-5072. doi: 10.1128/AEM.03006-05

Ellis, J. E., Lindmark, D. G., Williams, A. G., and Lloyd, D. (1994). Polypeptides of hydrogenosome-enriched fractions from rumen ciliate protozoa and 
trichomonads: immunological studies. FEMS Microbiol. Lett. 117, 211-216. doi: 10.1111/j.1574-6968.1994.tb06767.x

Finlay, B., Embley, T., and Fenchel, T. (1993). A new polymorphic methanogen, closely related to Methanocorpusculum parvum, living in stable symbiosis within the anaerobic ciliate Trimyema sp. Microbiology 139, 371-378. doi: 10.1099/00221287-139-2-371

Finlay, B. J., Esteban, G., Clarke, K. J., Williams, A. G., Embley, T. M., and Hirt, R. P. (1994). Some rumen ciliates have endosymbiotic methanogens. FEMS Microbiol. Lett. 117, 157-161. doi: 10.1111/j.1574-6968.1994.tb06758.x

Firkins, J. L., Yu, Z., and Morrison, M. (2007). Ruminal nitrogen metabolism: perspectives for integration of microbiology and nutrition for dairy. J. Dairy Sci. 90(Suppl. 1), E1-E16. doi: 10.3168/jds.2006-518

Fondevila, M., and Dehority, B. A. (2001). Preliminary study on the requirements of Entodinium exiguum and E. caudatum for live or dead bacteria when cultured in vitro. Reprod. Nutr. Dev. 41, 41-46. doi: 10.1051/rnd:2001110

Gong, J., Qing, Y., Zou, S., Fu, R., Su, L., Zhang, X., et al. (2016). Protist-bacteria associations: Gammaproteobacteria and Alphaproteobacteria are prevalent as digestion-resistant bacteria in ciliated protozoa. Front. Microbiol. 7:498. doi: $10.3389 /$ fmicb. 2016.00498

Görtz, H. D. (2001). Intracellular bacteria in ciliates. Int. Microbiol. 4, 143-150. doi: 10.1007/s10123-001-0029-9

Görtz, H. D., and Brigge, T. (1998). Intracellular bacteria in protozoa. Naturwissenschaften 85, 359-368. doi: 10.1007/s001140050517

Greene, C. H. (1983). Selective predation in freshwater zooplankton communities. Int. Rev. Hydrobiol. 68, 297-315. doi: 10.1002/iroh.19830680302

Henderson, G., Cox, F., Ganesh, S., Jonker, A., Young, W., Collaborators, G. R. C., et al. (2015). Rumen microbial community composition varies with diet and host, but a core microbiome is found across a wide geographical range. Sci. Rep. 5:14567. doi: 10.1038/srep14567

Hino, T., and Kametaka, M. (1977). Gnotobiotic and axenic cultures of a rumen protozoon, Entodinium caudatum. J. Gen. Appl. Microbiol. 23, 37-48.

Hubber, A., Vergunst, A. C., Sullivan, J. T., Hooykaas, P. J., and Ronson, C. W. (2004). Symbiotic phenotypes and translocated effector proteins of the Mesorhizobium loti strain R7A VirB/D4 type IV secretion system. Mol. Microbiol. 54, 561-574. doi: 10.1111/j.1365-2958.2004.04292.x

Irbis, C., and Ushida, K. (2004). Detection of methanogens and Proteobacteria from a single cell of rumen ciliate protozoa. J. Gen. Appl. Microbiol. 50, 203-212. doi: 10.2323/jgam. 50.203

Kigerl, K. A., Hall, J. C., Wang, L., Mo, X., Yu, Z., and Popovich, P. G. (2016). Gut dysbiosis impairs recovery after spinal cord injury. J. Exp. Med. 213, 2603-2620. doi: $10.1084 /$ jem. 20151345

Kim, M., and Yu, Z. (2012). Quantitative comparisons of select cultured and uncultured microbial populations in the rumen of cattle fed different diets. J. Anim. Sci. Biotechnol. 3:28. doi: 10.1186/2049-1891-3-28

Kinner, N., Harvey, R., Blakeslee, K., Novarino, G., and Meeker, L. (1998). Sizeselective predation on groundwater bacteria by nanoflagellates in an organiccontaminated aquifer. Appl. Environ. Microbiol. 64, 618-625.

Lane, D. (1991). "16S/23S rRNA sequencing," in Nucleic Acid Techniques in Bacterial Systematics, eds E. Stackebrandt and M. Goodfellow (New York, NY: John Wiley), 115-175.

Lloyd, D., Williams, A. G., Amann, R., Hayes, A. J., Durrant, L., and Ralphs, J. R. (1996). Intracellular prokaryotes in rumen ciliate protozoa: detection by confocal laser scanning microscopy after in situ hybridization with fluorescent $16 \mathrm{~S}$ rRNA probes. Eur. J. Protistol. 32, 523-531. doi: 10.1016/S0932-4739(96)80011-3

Lozupone, C., and Knight, R. (2005). UniFrac: a new phylogenetic method for comparing microbial communities. Appl. Environ. Microbiol. 71, 8228-8235. doi: 10.1128/AEM.71.12.8228-8235.2005

Lutz, C., Tay, Q. X. M., Sun, S., and McDougald, D. (2015). Draft genome sequence of Shewanella sp. strain CP20. Genome Announc. 3:e00256-15. doi: 10.1128/genomeA.00256-15

Mackie, R. I. (2002). Mutualistic fermentative digestion in the gastrointestinal tract: diversity and evolution. Integr. Comp. Biol. 42, 319-326. doi: 10.1093/icb/42.2.319

Martinele, I., Silva, L. F., D’agosto, M., Muniz, E. N., Sá, J. L. D., and Santos, G. R. D. A. (2014). Abundance and diversity of rumen protozoa in lambs fed Gliricidia sepium silage. Rev. Bras. Zoot. 43, 436-439. doi: $10.1590 /$ S1516-35982014000800006
Matz, C., and Kjelleberg, S. (2005). Off the hook - how bacteria survive protozoan grazing. Trends Microbiol. 13, 302-307. doi: 10.1016/j.tim.2005.05.009

Morgavi, D. P., Jouany, J. P., Martin, C., and Ranilla, M. J. (2006). Archaeal community structure diversity in the rumen of faunated and defaunated sheep. Int. Congr. Ser. 1293, 127-130. doi: 10.1016/j.ics.2006.01.019

Mosoni, P., Martin, C., Forano, E., and Morgavi, D. P. (2011). Longterm defaunation increases the abundance of cellulolytic ruminococci and methanogens but does not affect the bacterial and methanogen diversity in the rumen of sheep. J. Anim. Sci. 89, 783-791. doi: 10.2527/jas.2010-2947

Newbold, C. J., De La Fuente, G., Belanche, A., Ramos-Morales, E., and McEwan, N. R. (2015). The role of ciliate protozoa in the rumen. Front. Microbiol. 6:1313. doi: 10.3389/fmicb.2015.01313

Newbold, C. J., Lassalas, B., and Jouany, J. P. (1995). The importance of methanogens associated with ciliate protozoa in ruminal methane production in vitro. Lett. Appl. Microbiol. 21, 230-234. doi: 10.1111/j.1472-765X.1995.tb01048.x

Nocker, A., Sossa-Fernandez, P., Burr, M. D., and Camper, A. K. (2007). Use of propidium monoazide for live/dead distinction in microbial ecology. Appl. Environ. Microbiol. 73, 5111-5117. doi: 10.1128/AEM.02987-06

Ozutsumi, Y., Tajima, K., Takenaka, A., and Itabashi, H. (2005). The effect of protozoa on the composition of rumen bacteria in cattle using $16 \mathrm{~S}$ rRNA gene clone libraries. Biosci. Biotechnol. Biochem. 69, 499-506. doi: 10.1271/bbb.69.499

Ozutsumi, Y., Tajima, K., Takenaka, A., and Itabashi, H. (2006). Real-time PCR detection of the effects of protozoa on rumen bacteria in cattle. Curr. Microbiol. 52, 158-162. doi: 10.1007/s00284-005-0266-9

Park, T., Meulia, T., Firkins, J. L., and Yu, Z. (2017). Inhibition of the rumen ciliate Entodinium caudatum by antibiotics. Front. Microbiol. 8:1189. doi: 10.3389/fmicb.2017.01189.

Petri, R. M., Schwaiger, T., Penner, G. B., Beauchemin, K. A., Forster, R. J., McKinnon, J. J., et al. (2013). Characterization of the core rumen microbiome in cattle during transition from forage to concentrate as well as during and after an acidotic challenge. PLoS ONE 8:e83424. doi: 10.1371/journal.pone.0083424

Pukatzki, S., Ma, A. T., Sturtevant, D., Krastins, B., Sarracino, D., Nelson, W. C., et al. (2006). Identification of a conserved bacterial protein secretion system in Vibrio cholerae using the Dictyostelium host model system. Proc. Nat. Acad. Sci. U.S.A. 103, 1528-1533. doi: 10.1073/pnas.0510322103

Qu, J.-H., and Yuan, H. L. (2008). Sediminibacterium salmoneum gen. nov., sp. nov., a member of the phylum Bacteroidetes isolated from sediment of a eutrophic reservoir. Int. J. Syst. Evol. Microbiol. 58, 2191-2194. doi: 10.1099/ijs.0.65514-0

Regensbogenova, M., McEwan, N., Javorsky, P., Kisidayova, S., Michalowski, T., Newbold, C., et al. (2004). A re-appraisal of the diversity of the methanogens associated with the rumen ciliates. FEMS Microbiol. Lett. 238, 307-313. doi: 10.1111/j.1574-6968.2004.tb09771.x

Shinzato, N., Watanabe, I., Meng, X. Y., Sekiguchi, Y., Tamaki, H., Matsui, T., et al. (2007). Phylogenetic analysis and fluorescence in situ hybridization detection of archaeal and bacterial endosymbionts in the anaerobic ciliate Trimyema compressum. Microb. Ecol. 54, 627-636. doi: 10.1007/s00248-007-9218-1

Soldo, A. (1987). Parauronema acutum and its xenosomes: a model system. J. Eukaryot. Microbiol. 34, 447-451. doi: 10.1111/j.1550-7408.1987.tb03212.x

Sylvester, J. T., Karnati, S. K. R., Yu, Z., Morrison, M., and Firkins, J. L. (2004). Development of an assay to quantify rumen ciliate protozoal biomass in cows using real-time PCR. J. Nutr. 134, 3378-3384. doi: 10.1093/jn/134.12. 3378

Tamura, K., Stecher, G., Peterson, D., Filipski, A., and Kumar, S. (2013). MEGA6: molecular evolutionary genetics analysis version 6.0. Mol. Biol. Evol. 30, 2725-2729. doi: 10.1093/molbev/mst197

Tokura, M., Chagan, I., Ushida, K., and Kojima, Y. (1999). Phylogenetic study of methanogens associated with rumen ciliates. Curr. Microbiol. 39, 123-128. doi: $10.1007 / \mathrm{s} 002849900432$

Tokura, M., Ushida, K., Miyazaki, K., and Kojima, Y. (1997). Methanogens associated with rumen ciliates. FEMS Microbiol. Ecol. 22, 137-143. doi: 10.1111/j.1574-6941.1997.tb00365.x

Tóthová, T., Piknová, M., Kišidayová, S., Javorský, P., and Pristaš, P. (2008). Distinctive archaebacterial species associated with anaerobic rumen protozoan Entodinium caudatum. Folia Microbiol. 53, 259-262. doi: $10.1007 / \mathrm{s} 12223-008-0039-5$ 
Tymensen, L. D., Beauchemin, K. A., and McAllister, T. A. (2012). Structures of free-living and protozoa-associated methanogen communities in the bovine rumen differ according to comparative analysis of $16 \mathrm{~S}$ rRNA and mcrA genes. Microbiology 158, 1808-1817. doi: 10.1099/mic.0.057984-0

Ushida, K. (2010). "Symbiotic methanogens and rumen ciliates," in (Endo) Symbiotic Methanogenic Archaea, ed J. H. P. Hackstein (Heidelberg: Springer), 25-34.

Ushida, K., Jouany, J., and Demeyer, D. (1991). "Effects of presence or absence of rumen protozoa on the efficiency of utilization of concentrate and fibrous feeds," in Physiological Aspects of Digestion and Metabolism in Ruminants (Elsevier), 625-654.

Valle, E. R., Henderson, G., Janssen, P. H., Cox, F., Alexander, T. W., and McAllister, T. A. (2015). Considerations in the use of fluorescence in situ hybridization (FISH) and confocal laser scanning microscopy to characterize rumen methanogens and define their spatial distributions. Can. J. Microbiol. 61, 417-428. doi: 10.1139/cjm-2014-0873

van Hoek, A. H., Van Alen, T. A., Sprakel, V. S., Leunissen, J. A. M., Brigge, T., Vogels, G. D., et al. (2000). Multiple acquisition of methanogenic archaeal symbionts by anaerobic ciliates. Mol. Biol. Evol. 17, 251-258. doi: 10.1093/oxfordjournals.molbev.a026304

van Hoek, A. H., Sprakel, V. S., Van Alen, T. A., Theuvenet, A. P., Vogels, G. D., and Hackstein, J. H. (1999). Voltage-dependent reversal of anodic galvanotaxis in Nyctotherus ovalis. J. Eukaryot. Microbiol. 46, 427-433. doi: 10.1111/j.1550-7408.1999.tb04623.x

Vannini, C., Petroni, G., Schena, A., Verni, F., and Rosati, G. (2003). Wellestablished mutualistic associations between ciliates and prokaryotes might be more widespread and diversified than so far supposed. Eur. J. Protistol. 39, 481-485. doi: 10.1078/0932-4739-00024

Váradyová, Z., Kisidayova, S., Zelenák, I., and Siroká, P. (2001). Effect of antibiotics, 2-bromoethanesulfonic acid and pyromellitic diimide on methanogenesis in rumen ciliate cultures in vitro. Arch. Tierernahr. 54, 33-46. doi: 10.1080/17450390109381964

Vogels, G. D., Hoppe, W. F., and Stumm, C. K. (1980). Association of methanogenic bacteria with rumen ciliates. Appl. Environ. Microbiol. 40, 608-612.

Wagener, S., Bardele, C., and Pfennig, N. (1990). Functional integration of Methanobacterium formicicum into the anaerobic ciliate Trimyema compressum. Arch. Microbiol. 153, 496-501. doi: 10.1007/BF00248433

Wang, L., Oda, Y., Grewal, S., Morrison, M., Michel, F. C., and Yu, Z. (2012). Persistence of resistance to erythromycin and tetracycline in swine manure during simulated composting and lagoon treatments. Microb. Ecol. 63, 32-40. doi: 10.1007/s00248-011-9921-9

Wang, Q., Garrity, G. M., Tiedje, J. M., and Cole, J. R. (2007). Naive Bayesian classifier for rapid assignment of rRNA sequences into the new bacterial taxonomy. Appl. Environ. Microbiol. 73, 5261-5267. doi: 10.1128/AEM.00062-07

Watanabe, T., Asakawa, S., Nakamura, A., Nagaoka, K., and Kimura, M. (2004). DGGE method for analyzing 16S rDNA of methanogenic archaeal community in paddy field soil. FEMS Microbiol. Lett. 232, 153-163. doi: 10.1016/S0378-1097(04)00045-X

White, P. A., Kalff, J., Rasmussen, J. B., and Gasol, J. M. (1991). The effect of temperature and algal biomass on bacterial production and specific growth rate in freshwater and marine habitats. Microb. Ecol. 21, 99-118. doi: 10.1007/BF02539147

Williams, A., and Coleman, G. (1997). “The rumen protozoa," in The Rumen Microbial Ecosystem (Springer), 73-139.

Wright, A.-D. G., and Pimm, C. (2003). Improved strategy for presumptive identification of methanogens using 16S riboprinting. J. Microbiol. Methods 55, 337-349. doi: 10.1016/S0167-7012(03)00169-6

Xia, Y., Kong, Y. H., Seviour, R., Forster, R. J., Kisidayova, S., and McAllister, T. A. (2014). Fluorescence in situ hybridization probing of protozoal Entodinium spp. and their methanogenic colonizers in the rumen of cattle fed alfalfa hay or triticale straw. J. Appl. Microbiol. 116, 14-22. doi: 10.1111/jam. 12356

Yánez-Ruiz, D. R., Williams, S., and Newbold, C. J. (2007). The effect of absence of protozoa on rumen biohydrogenation and the fatty acid composition of lamb muscle. Br. J. nutr. 97, 938-948. doi: 10.1017/S0007114507675187

Yarlett, N., Coleman, G. S., Williams, A. G., and Lloyd, D. (1984). Hydrogenosomes in known species of rumen entodiniomorphid protozoa. FEMS Microbiol. Lett. 21, 15-19. doi: 10.1111/j.1574-6968.1984.tb00178.x

Yu, Z., Michel, F. C., Hansen, G., Wittum, T., and Morrison, M. (2005). Development and application of real-time PCR assays for quantification of genes encoding tetracycline resistance. Appl. Environ. Microbiol. 71, 6926-6933. doi: 10.1128/AEM.71.11.6926-6933.2005

$\mathrm{Yu}$, Z., and Morrison, M. (2004). Improved extraction of PCR-quality community DNA from digesta and fecal samples. BioTechniques 36, 808-812. doi: 10.2144/04365ST04

Conflict of Interest Statement: The authors declare that the research was conducted in the absence of any commercial or financial relationships that could be construed as a potential conflict of interest.

Copyright (c) 2018 Park and Yu. This is an open-access article distributed under the terms of the Creative Commons Attribution License (CC BY). The use, distribution or reproduction in other forums is permitted, provided the original author(s) and the copyright owner(s) are credited and that the original publication in this journal is cited, in accordance with accepted academic practice. No use, distribution or reproduction is permitted which does not comply with these terms. 